\title{
New Excavations at Umhlatuzana Rockshelter, KwaZulu-Natal, South Africa: a Stratigraphic and Taphonomic Evaluation
}

\author{
Irini Sifogeorgaki $(\mathbb{D} \cdot$ Victor Klinkenberg • Irene \\ Esteban • May Murungi • Andrew S. Carr • Valentijn \\ B. van den Brink • Gerrit L. Dusseldorp
}

Accepted: 2 September 2020 / Published online: 26 September 2020

(C) The Author(s) 2020
I. Sifogeorgaki $(\bowtie) \cdot$ V. Klinkenberg $\cdot$ G. L. Dusseldorp

Faculty of Archaeology, Leiden University, Leiden, the

Netherlands

e-mail: e.sifogeorgakis@arch.leidenuniv.nl

I. Esteban · M. Murungi

Evolutionary Studies Institute, University of the Witwatersrand, Johannesburg, South Africa

I. Esteban

African Centre for Coastal Palaeoscience, Nelson Mandela University, Port Elizabeth, South Africa

\section{A. S. Carr}

School of Geography, Geology and the Environment, University of Leicester, Leicester, UK

V. B. van den Brink

VUhbs Archeologie, Amsterdam, the Netherlands

\section{G. L. Dusseldorp}

Palaeo-Research Institute, University of Johannesburg,

Johannesburg, South Africa geoarchaeological study of the site to clarify the site formation processes. Here, we present the results of the excavation and propose a revised stratigraphic division of the Pleistocene sequence based on field observations, sedimentological (particle size) analyses, and cluster analysis. The taphonomy of the site is assessed through phytolith and geochemical $(\mathrm{pH}$, loss on ignition, stable carbon isotope) analyses. The results indicate a consistent sedimentological environment characterized by in situ weathering. The analysis of the pieceplotted finds demonstrates semihorizontal layering of archaeologically dense zones and more sterile ones. There was no indication of large-scale postdepositional sediment movement. We show that the low-density archaeological horizons in the upper part of the Pleistocene sequence are best explained by the changing patterns of sedimentation rate.

Résumé L'abri sous-roche d'Umhlatuzana contient une séquence d'habitation enjambant les 70,000 dernières années. Le site est. un des rares exemples d'occupation couvrant la transition du " Middle Stone Age » à « Later Stone Age » dans l'Afrique du Sud. Une bonne compréhension des processus de formation du site est. donc importante pour l'étude du développement d'Homo sapiens. Le site a été fouillé pour la première fois dans les années 1980 par Jonathan Kaplan; il a suggéré que l'intégrité des gisement archéologiques du « Middle Stone Age » et de la transition au « Later Stone Age » était compromise par le grand mouvement de sédiments. Nous avons lancé une nouvelle étude géoarchéologie en 2018 avec l'objectif de clarifier les 
processus de formation du site. Nous présentons les premiers résultats de notre étude et proposons une division stratigraphique révisée de la séquence du Pléistocène. Notre analyse combine des observations stratigraphiques, des analyses sédimentologique (granulométrie), et une analyse en grappes de la distribution des matériaux archéologiques. Nous avons également évalue la taphonomie du site à l'aide d'analyses phytolithiques et géochimiques $(\mathrm{pH}$, matière volatile en suspension, isotope de carbone stable). Les résultats indiquent un environnement sédimentologique cohérent caractérisé par une altération in situ. L'analyse spatiale des découvertes montre une superposition semihorizontale de zones denses et de zones plus stériles. Il n'y avait aucune indication de mouvements à grande échelle de sédiments après leur dépôt. Nous montrons que les horizons archéologiques de faible densité dans la partie supérieure de la séquence du Pléistocène s'expliquent le mieux par l'évolution des modèles de vitesse de sédimentation.

Keywords Middle Stone Age · Later Stone Age · Late Pleistocene · Geoarchaeology · Occupation history · Umhlatuzana rockshelter

\section{Introduction}

Umhlatuzana rockshelter is one of the few sites in southern Africa with a continuous occupation sequence spanning the last 70,000 years. It was at the beginning of this period that "modern" human behaviors appeared, represented by the Still Bay and Howiesons Poort industries, both of which are represented at the site (Archer et al. 2016; Högberg and Lombard 2016a, b; Kaplan 1990; Lombard 2007; Lombard et al. 2010; Mohapi 2013; McCall and Thomas 2009). Located in KwaZulu-Natal (eastern South Africa), the site contains important information on the techno-cultural sequence of the South African Middle Stone Age (MSA) and Later Stone Age (LSA). The Pleistocene archaeological sites of the region are less abundant and not well-known compared to southwest South Africa, which has dominated the techno-cultural study of the period (e.g., Deacon 1984; Lombard et al. 2012; Volman 1981; Wurz 2002). Thus, Umhlatuzana occupies a critical position due to its geographical location and because its MSA and LSA deposits bridge the gaps in archaeological sequences at other important sites.
Recent work in KwaZulu-Natal and the surrounding areas has brought to light evidence of early sophisticated behavior from the MSA (Fig. 1). For instance, Sibudu Cave has yielded important MSA remains (Backwell et al. 2008; Hodgkiss 2013; Rots et al. 2017; Wadley 2007; Wadley et al. 2011). Its occupation commenced earlier than that at Umhlatuzana, but Sibudu lacks deposits from the MSA-LSA transition and the subsequent LSA (Wadley and Jacobs 2006). Another important site, Umbeli Belli, has so far yielded archaeological remains from the later parts of the MSA and the Pleistocene LSA (Bader et al. 2016, 2018). Border Cave has an important MSA occupation sequence and has yielded the earliest ages for the MSA/LSA transition (d'Errico et al. 2012; Villa et al. 2012). Its occupation ceased after the transitional phase, and no evidence from the later Pleistocene LSA has been recovered. At Sehonghong in Lesotho, occupation started with the Howiesons Poort and continued up to historical times (Mitchell 1994; Stewart et al. 2016). Sehonghong does not preserve pre-Howiesons Poort occupations and has an occupation hiatus during the Last Glacial Maximum (Pargeter et al. 2017). Finally, Waterfall Bluff shows human occupation starting at least as early as $37.6 \mathrm{ka}$ and lasting through the Middle Holocene (Fisher et al. 2020).

The continuous sequence at Umhlatuzana has the potential to enable us to relate all these occupational pulses to each other. Umhlatuzana is one of the few sites with occupation across the MSA-LSA transition (Loftus et al. 2019; Mackay et al. 2014; Mitchell 2008; Villa et al. 2012). However, at present, transitional MSA-LSA assemblages are not well understood in southern Africa, both in terms of technological organization and chronology. The earliest LSA in the region has only been informally characterized (Lombard et al. 2012; Mackay et al. 2014). Technological variability appears considerable, and assemblages are spread across great distances. It is unclear how the earliest LSA assemblages relate to transitional MSA-LSA assemblages.

Rescue excavation of the site was conducted in 1985 to mitigate the site's potential destruction from highway construction (Kaplan 1989, 1990). Unfortunately, due to uncertainties about the stratigraphic integrity of Umhlatuzana's sedimentary sequence, the archaeological assemblages have been overlooked in the discourse of the MSA/LSA transition (cf. Deacon and Deacon 1999, Mitchell 2002). Kaplan (1990) reported that no visible stratigraphic boundaries were observed in the 
Fig. 1 Map of South Africa, showing the location of Umhlatuzana rockshelter and its relative position to other important Middle and Later Stone Age sites discussed in the text

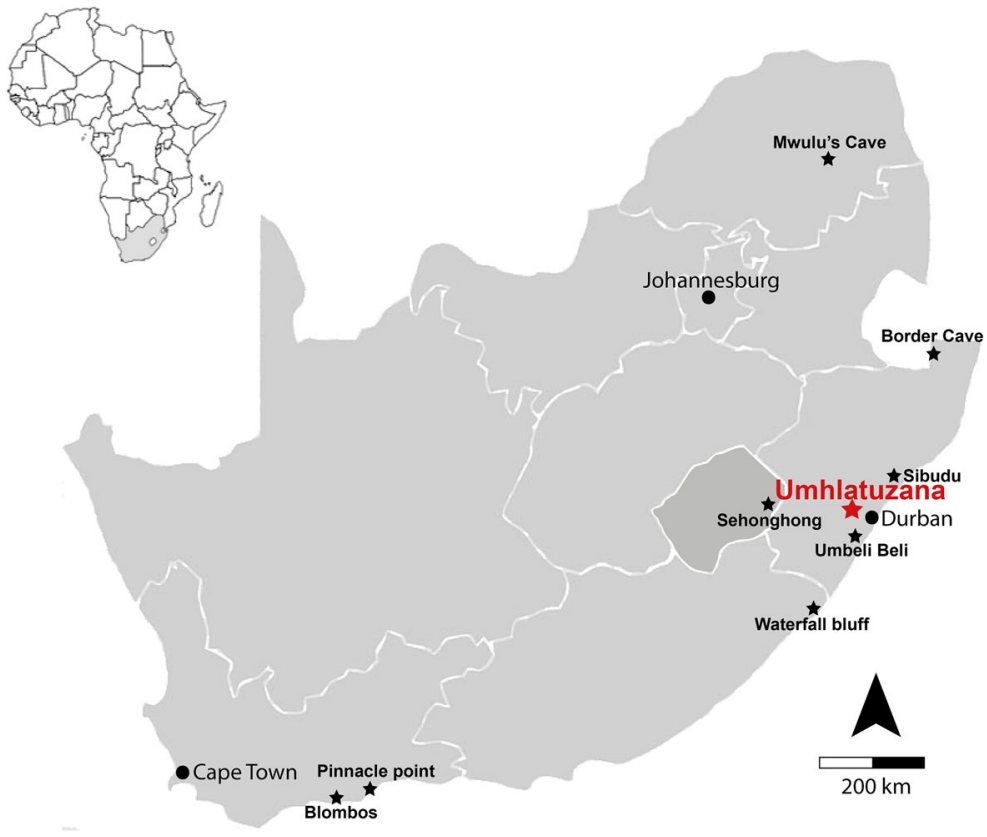

Pleistocene part of the sequence and that the deposits were excavated in artificial spits. Moreover, a lateral difference in sediment characteristics was observed within the upper MSA and MSA/LSA transitional spits, casting doubt on assemblage integrity (Kaplan 1990, p. 6). Subsequent optically stimulated luminescence (OSL) dating showed moderate amounts of overdispersion (intergrain scatter not accounted for by individual measurement uncertainties), which implied that sedimentary mixing of deposits of different ages was limited to relatively small-scale events (Lombard et al. 2010).

In 2018, we initiated a geoarchaeological project to study the Pleistocene stratigraphy and depositional history of the site. This fits the trend of recent studies that focus on understanding the depositional history of MSA sites in South Africa (e.g., Backwell et al. 2018; de la Peña et al. 2019; Goldberg et al. 2009; Haaland et al. 2017; Henshilwood et al. 2014; Larbey et al. 2019; Lotter et al. 2016; Miller et al. 2013). Our fieldwork has three interrelated goals. The first is to determine whether large-scale sediment movement affected the Pleistocene sedimentary sequence and to arrive at a detailed stratigraphic subdivision of the sediments. The second is to assess preservation conditions at the site, using geochemical methods, and therefore evaluate the previous conclusion that organic preservation was poor in the Pleistocene deposits (Kaplan 1990). Third, we seek to assess whether, and to what degree, the shelter surface was sloped during deposition. Answering these questions is key to contextualizing the assemblages from the previous excavations, and to establishing whether assemblages from spits at the same horizontal level but different squares are contemporaneous.

We use cluster analysis of piece-plotted archaeological finds, and sedimentological, mineralogical, and geochemical analyses, to achieve the above objectives. Our results replicate many of Kaplan's (1990) observations but do not support his idea of the large-scale depositional movement of sediments. We propose a new division of the Pleistocene sequence into stratigraphic units and conclude that the shelter's surface appears to have been largely horizontal. This in-depth understanding of Umhlatuzana's sedimentary sequence highlights the importance of the site for studying the development of modern human technological behaviors in southern Africa.

\section{Site Setting}

Umhlatuzana rockshelter is located between Durban and Pietermaritzburg in KwaZulu-Natal, South Africa (Fig. 1). The site is a shallow, northeast-facing rockshelter $47 \mathrm{~m}$ long, $8 \mathrm{~m}$ wide, and at the point of the excavation, $17.5 \mathrm{~m}$ high. It is located in the Umhlatuzana River valley, approximately $100 \mathrm{~m}$ above the current riverbed, 
within Natal Group sandstones and quartzites $(\sim 490$ Ma; Marshall 1994). The lithostratigraphic characteristics of the sandstones make them relatively resistant to erosion and weathering processes, resulting in a rugged landscape with abundant overhanging walls. The river has been incising a deep valley since the early Pliocene (King 1982). Based on river incision rates in South Africa (Erlanger et al. 2009), the site was always high above the river bed during its phase of human occupation.

The site is currently situated in a coastal scarp forest (dominated by $\mathrm{C}_{3}$ vegetation), with grassland (dominated by $\mathrm{C}_{4}$ plants) occurring on the flat table-lands nearby (Mucina and Rutherford 2006). Located in South Africa's summer rainfall zone, the region's annual rainfall ranges from 750 to $1,350 \mathrm{~mm}$, with $75 \%$ of the total occurring between November and March ( $\mathrm{Nel} 2009$ ). Although sheltered by large trees, the rockshelter receives sunlight throughout much of the day (Fig. 2). During rain showers, we observed that the deposits are protected by the rockshelter overhang and remain dry.

\section{Research History}

The site was discovered in 1982 by Dr. Rodney Maud during the construction of the Johannesburg-Durban N3 highway. It was excavated in 1985 by Jonathan Kaplan (1989, 1990), who opened a trench of $6 \mathrm{~m}^{2}$. He excavated $4 \mathrm{~m}^{2}$ of this to the bedrock $(\sim 2.5 \mathrm{~m}$ below the shelter surface) and the other $2 \mathrm{~m}^{2}$ to $1.5-\mathrm{m}$ depth. He documented a Holocene sequence containing finely stratified sandy deposits that included combustion features. However, from $\sim 50 \mathrm{~cm}$ below the surface, stratigraphic divisions were no longer visible, and this part of the sequence was excavated in artificial spits of 5$10 \mathrm{~cm}$.

The uppermost part of the occupation sequence is dated to the last 2,000 years. It is represented by final Later Stone Age assemblages, with indications for contact with Iron Age societies in the form of pottery sherds and Achatina beads (Kaplan 1990). The uppermost Pleistocene and lowermost Holocene sediments contain a Robberg industry. This industry, characterized by the production of standardized bladelets and a paucity of retouched pieces, is correlated with South African MIS 2 occupations, 12-18 kya (Lombard et al. 2012; for a perspective from eastern South Africa, see Bader et al. 2020). At Umhlatuzana, Kaplan obtained radiometric ages for the uppermost Robberg sediments that were

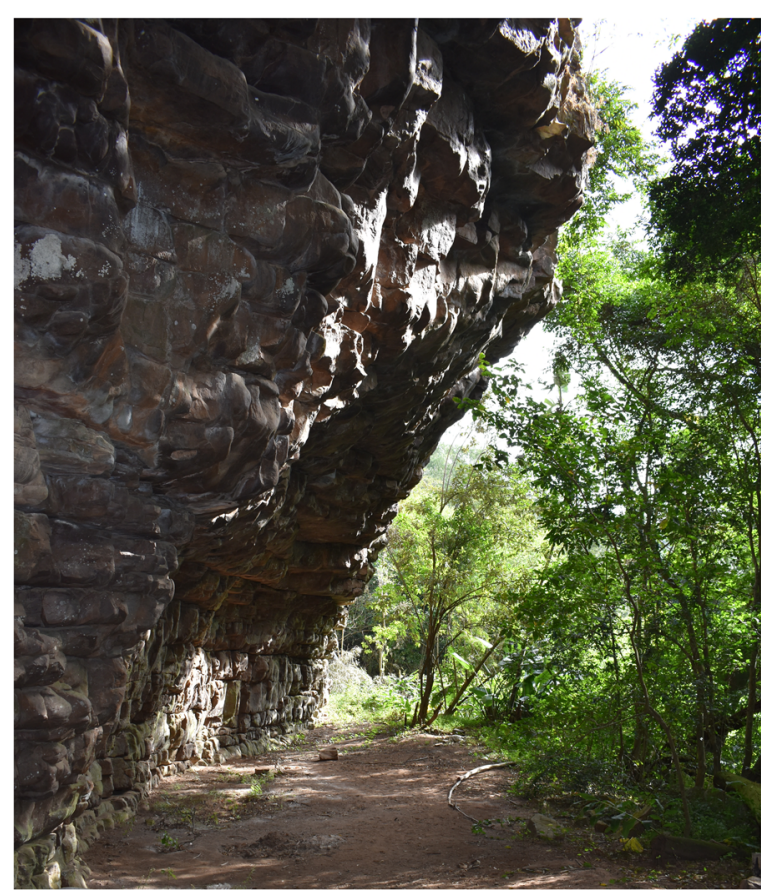

Fig. 2 View of Umhlatuzana rockshelter looking northwest

younger than those known elsewhere in South Africa. $\mathrm{He}$, therefore, called these assemblages late Robberg. Further, the radiometric ages for the lowermost Robberg levels at the site were older than those known from other sites in southern Africa. These were, therefore, dubbed early Robberg. Both the early and the late Robberg at the site fit the standard definitions of Robberg technology (Kaplan 1990, p. 85).

The transitional MSA and LSA lithic assemblages underlying the Robberg were also excavated. These assemblages are important as few sites in the region have the record of this transition. The MSA assemblages contain hollow-based points and are called Late MSA by Kaplan (1990). At Sibudu, assemblages containing hollow-based points are characterized as final MSA by Wadley (2005), while the underlying assemblages characterized by unifacial points are called Late MSA (Villa et al. 2005; Wadley 2005; also see Conard et al. 2012; Lombard et al. 2012). Below the Late MSA, Kaplan (1990) described assemblages belonging to the Howiesons Poort technocomplex, and below that, the Still Bay. Both of these technocomplexes have been associated with the early appearance of the so-called modern human behaviors (Henshilwood 2012). The Howiesons Poort in Umhlatuzana is characterized by the 
production of backed segments that were likely hafted using complex recipes (Lombard 2007). The analysis of segments from Umhlatuzana and Sibudu led to the conclusion that bow-and-arrow hunting was practiced during the Howiesons Poort (Lombard and Phillipson 2010, also see Lombard 2011). This period has also been associated with the development of innovative foraging behaviors such as trapping (Lombard 2011; Wadley 2010; also see Dusseldorp 2012). Not only the foraging strategies were innovative, but the production of a bow-and-arrow set was even more complex than other weapon systems ever known before that time (Lombard and Haidle 2012). The Still Bay at Umhlatuzana is characterized by the production of bifacial leaf points (Högberg and Lombard 2016a, b; also see Villa et al. 2009). At Blombos Cave in southwest South Africa, the Still Bay is associated with engraved pieces of ochre and the production of jewelry, demonstrating the presence of early symbolic behavior (Henshilwood 2012). The Still Bay technocomplex is also associated with "high-tech" behaviors. At Umhlatuzana and Blombos Cave, pressure flaking was practiced to aid in the production of finely shaped edges of points and for thinning bifacial points (Högberg and Lombard 2016a). Further, at Blombos Cave, the silcrete used in leaf point production was heat-treated to improve knapping suitability (Mourre et al. 2010).

With its Howiesons Poort and Still Bay assemblages, Umhlatuzana contributes to understanding the development of both technological sophistication and symbolic behavior. Single grain OSL ages were obtained for the Still Bay, Howiesons Poort, and Late MSA sediments (Jacobs et al. 2008; Lombard et al. 2010). The most populous of the equivalent dose $\left(D_{e}\right)$ clusters identified from finite mixture modeling analyses produced ages consistent with those of other Howiesons Poort $(\sim$ 60,000 BP) and Still Bay ( 70,000 BP) sites (Jacobs and Roberts 2008; Lombard et al. 2010).

Site inspections in 2014 revealed that the site had been vandalized; sandbags had been removed from the trench, and illegal excavations had taken place. The northern profile had been undercut by $70 \mathrm{~cm}$ up to $2.20 \mathrm{~m}$ depth, and the eastern section had been cut back by around $30 \mathrm{~cm}$ (Anderson 2014). The reports of vandalism, combined with the potential destruction of the site as the South African National Roads Agency prepared to widen the N3 highway, prompted the current investigation.
Stratigraphic and Taphonomic Issues

Kaplan documented a 2.5-m stratigraphic sequence (Kaplan 1990). Within the Pleistocene part of the sequence, one major stratigraphic boundary, between socalled Red Brown and Purple Brown Sand deposits, was observed. The Red Brown Sands (RBS) occupy the north side (i.e., shelter mouth) of the site, and the Purple Brown Sands (PBS) are present toward the back of the shelter, partially underlying the RBS (Kaplan 1990, p. 7). The contact between them was proposed to represent a single postdepositional event of rotational slipping, whereby during a wet phase, a large block of sediment shifted downwards along the talus slope (Kaplan 1990, p. 6-7). The archaeological materials excavated by Kaplan (1990) were collected in 5-10 cm-thick, horizontal spits.

The preservation of organic material in these deposits varies. Charcoal and bone are well-preserved in the Holocene deposits (Kaplan 1989, 1990). In the upper part of the Pleistocene deposits, faunal and charcoal remains are largely absent; they become slightly more numerous in some of the lowermost layers (Kaplan 1990, p. 68-70). An appraisal of the preservation conditions and the geochemical environment is needed to determine if the changing abundance of organic materials within the Pleistocene sediments is a product of changing human behavior or taphonomic processes.

\section{Materials and Methods}

\section{Excavation Protocol}

We conducted excavations in June-August 2018 and July-August 2019. Surface material was collected, and the profiles of the trench excavated by Kaplan (1990) were cleaned and documented. The geoarchaeological analysis of the deposits was then carried out; this focused on the western profile (Fig. 3) for several reasons:

- Detailed sediment descriptions and chronology of the western profile were provided in the initial excavation report (Kaplan 1990).

- The proposed postdepositional sediment movement was recorded in this section.

- The northern profile was in poor condition due to damage from vandalism. 
- The eastern profile is poorly visible due to tree roots and vandalism.

- The southern profile is stepped and therefore has limited exposure.

First, the excavation profiles were inspected for lateral and vertical differentiation. To achieve this, strong white artificial lighting was rigged to ensure optimal visibility and optimal description of the Pleistocene sediments. Sedimentary units were defined and characterized by their color (using the Revised Standard Soil Colour Charts 2010), texture, strength, plasticity, stickiness, and presence of inclusions (based on Kyrillidou [2006] and references therein). Additional observations on the nature of the stratigraphic boundaries and the presence of disturbances (i.e., roots, bioturbation) were recorded. The 1:10 scale stratigraphic drawings were created before and after the excavation. The thorough description of the sedimentary sequence aimed to define stratigraphic subdivisions and provide a further line of evidence as to the depositional and postdepositional history of the site. Visually identified stratigraphic entities were classified as units and identified by Arabic numerals.

Using a Sokkia Robotic Total Station (RTS), we identified the original grid system developed by Kaplan (1990). Following the original grid, three new squares of $50 \times 50 \mathrm{~cm}^{2}$ were projected and subsequently excavated on the western side of the previous trench, L2a, L2b, and L3a (Fig. 4). Square L3a was excavated up to $2.40 \mathrm{~m}$ depth (bedrock), and squares L2a and L2b were both excavated up to $2.04 \mathrm{~m}$ depth. Where possible, the natural stratigraphy was followed. Thick stratigraphic units were subdivided into $2-\mathrm{cm}$ spits to ensure stratigraphic control over finds and sieved materials.

Natural materials and artifacts $>2 \mathrm{~cm}$ (henceforth, "finds") were piece-plotted. All excavated sediments were systematically dry-sieved using nested $1 \mathrm{~mm}, 2 \mathrm{~mm}$, and $5 \mathrm{~mm}$ sieves and labeled by square, stratigraphic unit, and spit. This ensured the recovery of small materials. The flotation of the sieved material was implemented to recover macrobotanical remains. Fabric information was recorded for all finds $>5 \mathrm{~cm}$ using multiple measurements with the RTS. The dip and orientation of the finds were plotted using linear measurements for elongated finds $(>5 \mathrm{~cm}$ with an elongation index higher than 1:7, Bertan and Textier 1995).
Sampling Protocol

Twenty-three bulk sediment samples from the main stratigraphic units were collected for particle size and geochemical ( $\mathrm{pH}$, organic matter content) analyses (Table 2). Twenty-one archaeological sediment samples from the Pleistocene and Pleistocene/Holocene boundary deposits were collected from the western profile and analyzed for phytolith content and mineralogical composition. Five control samples were additionally collected to analyze their phytolith and mineralogical component: two from the top surface sediments and three modern surface soil samples from the vegetated areas outside the shelter's edge. Lastly, 28 samples were obtained for stable isotope analysis, consisting of 24 from the archaeological deposits and four from the sediments on the shelter's surface.

\section{Sediment Analyses}

This section covers particle size, $\mathrm{pH}$, Fourier transform infrared spectroscopy (FT-IR), organic content, elemental, and stable carbon isotope analyses.

\section{Particle Size Analysis}

To determine the character of the sediments, their source(s), mechanism(s) of sedimentation, and depositional environment(s), we analyzed the particle size distribution of 23 sediment samples (Karkanas and Goldberg 2018). We used a Helos KR laser diffraction sensor following the preparation protocol of the Free University Amsterdam Sediment Laboratory for "middle coarse sediments" with $<30 \%$ carbonate. Approximately $5 \mathrm{~g}$ of material was first treated with $5 \mathrm{ml}$ of $30 \%$ $\mathrm{H}_{2} \mathrm{O}_{2}$. Demineralized water was added to $100 \mathrm{ml}$, and the solution was boiled; $5 \mathrm{ml}$ of $10 \% \mathrm{HCl}$ was added, and the samples were boiled, diluted with water, and left standing overnight. After decantation down to $50 \mathrm{ml}$, the suspension was filled up to $100 \mathrm{ml}$ with water. About $300 \mathrm{mg} \mathrm{Na} \mathrm{P}_{2} \mathrm{O}_{7} \cdot 10 \mathrm{H}_{2} \mathrm{O}$ was added, and the samples were boiled. Particle size distributions were then characterized following Folk and Ward (1957).

\section{pH Analysis}

We conducted $\mathrm{pH}$ analysis to comprehend variability in the preservation of organic materials. The levels of acidity versus alkalinity of the sediment samples are 
Fig. 3 a Overview of the western profile of the $\mathrm{K}$ squares excavated by Kaplan (1990), prior to the 2018-2019 excavation highlighting the difference between the higher- and lower-moisture sediments and Pleistocene/Holocene boundary. $\mathbf{b}$ West profile of squares L2a, L2b, and L3a. c Upper hearth feature (units $\mathrm{H} 2$, $\mathrm{H} 3$, and H4). d Unifacial point from the Late MSA

Fig. 4 Site plan of Umhlatuzana rockshelter. White squares excavated in 1985 by Kaplan (1990). Squares L2a, L2b, and L3a excavated in 2018-2019
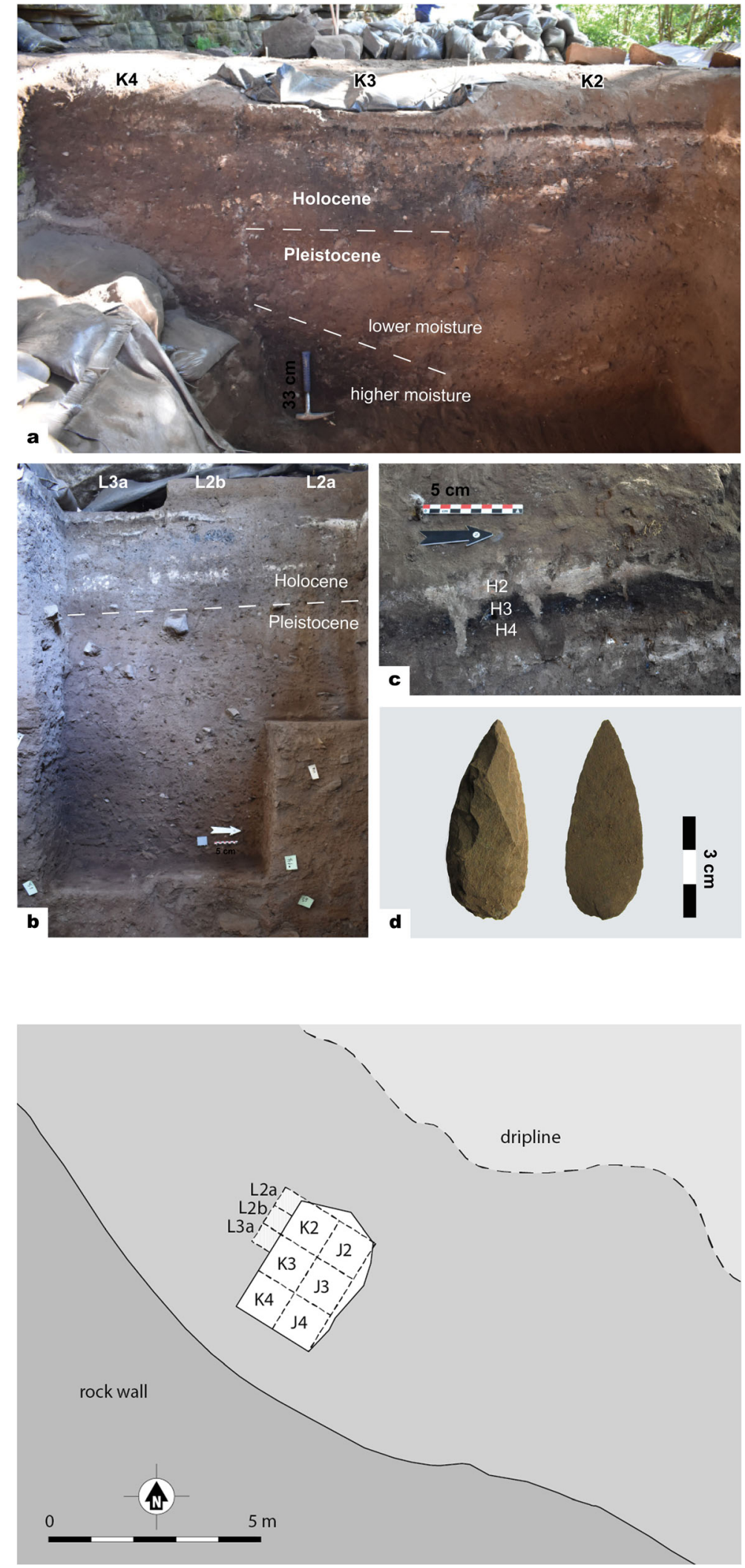
important indicators of the preservation conditions for organic materials (Pollard et al. 2007). The measurements were carried out in a 1:2 sediment:water solution, using a Fisher Scientific Accumet AB150. Three measurements were averaged for each sample. $\mathrm{pH}$ values are highly affected by the type of sediment, anthropogenic activities, and postdepositional microbiological activity whereby bacteria and fungi produce organic acids that reduce the $\mathrm{pH}$ of the sediments (Weiner 2010). All of these influence diagenetic processes on materials like bone, wood, phytoliths, mollusks, etc. (Garrison 2003). High pH levels (alkaline conditions) are associated with increased bone preservation while low levels (acidic conditions) result in better preservation of silica materials such as phytoliths (Garrison 2003; Pollard et al. 2007; Weiner 2010).

\section{FT-IR Analysis}

Fourier transform infrared spectroscopy (FT-IR) analysis was used to identify the bulk mineral components of a total of 26 samples to understand (1) the conditions that may have affected the state of preservation of phytoliths and (2) the mineralogical composition of the sediments. FT-IR has been extensively used in archaeological research for the identification of both crystalline and amorphous minerals, including organic materials (i.e., bone), minerals and precipitates (e.g., clay minerals, carbonates, sulfates, phosphates, nitrates), wood ash (e.g., pyrogenic calcite, charcoal, and opaline phytoliths), and materials exposed to elevated temperatures (see Weiner 2010). Samples were ground with an agate mortar and pestle. Spectra were obtained using an ALPHA platinum ATR single reflection diamond module (Bruker Alpha series) spectrometer. Phase identification was performed using the software OPUS 7.5 from Bruker by consulting standard literature (e.g., Madejová 2003; Müller et al. 2014; Sherman Hsu 1997; Vahur et al. 2016). The reference collection of FT-IR spectra of standard materials provided by the Kimmel Center for Archaeological Science, Weizmann Institute of Science (http://www.weizmann.ac. il/kimmel-arch/infrared-spectra-library) was consulted.

\section{Organic Content Analysis}

To determine the organic content of the sediments, loss on ignition (LOI) was employed using a Leco TGA 701. The organic content was measured at $550{ }^{\circ} \mathrm{C}$.
Comparative measurements of the organic matter throughout the sequence yield information on the preservation of the site and the presence of organic-rich formations such as palaeosols (Goldberg and MacPhail 2006). Anthropogenic activities also usually resulted in deposits with high organic content (Karkanas and Goldberg 2018).

\section{Elemental Analysis and Stable Carbon Isotope Analysis}

The total nitrogen content (TN), total carbon content (TC), total organic carbon (TOC), and $\delta^{13} \mathrm{C}_{\mathrm{TOC}}$ were determined via elemental analysis. Since part of the carbon in sediment samples is potentially geogenic, samples were analyzed with and without acid treatment. The acid-insoluble carbon (TOC) is considered the best representation of the organic carbon present in the sediments. TOC speaks to organic input/preservation in the sedimentary sequence and provides a point of comparison to LOI results. The ratio of ${ }^{12} \mathrm{C}$ to ${ }^{13} \mathrm{C}$ isotopes is expressed through the $\delta^{13} \mathrm{C}_{\mathrm{TOC}}$ metric (Ambrose 1986) and was obtained from the acid-treated samples.

In archaeological contexts, organic carbon as recorded in TOC and $\delta^{13} \mathrm{C}_{\mathrm{TOC}}$ is derived from both natural as well as anthropogenic inputs, such as firewood, and plant materials brought to the site (e.g., bedding, lipids from food preparation). Human agency may, therefore, impact the isotopic signatures of the plant materials observed at the site. Given the broader questions concerning the present site's stratigraphy and postdepositional history, we use the TOC and $\delta{ }^{13} \mathrm{C}_{\mathrm{TOC}}$ analyses to explore whether isotopically and/or geochemically distinct units can be identified (regardless of precise cause). These results are considered in light of data from contemporary soils in the immediate surroundings of the rockshelter.

Samples were sieved to $<2 \mathrm{~mm}$, freeze-dried, and then ground in a ball mill. Measurements for TOC involved an additional treatment with dilute hydrochloric acid (centrifuged, decanted, and repeatedly rinsed in deionized water) prior to freeze-drying. The samples were then encapsulated in tin cups and analyzed using a SerCon ANCA GSL elemental analyzer interfaced to a SerCon Hydra 20-20 continuous-flow isotope ratio mass spectrometer. All analyses were carried out in triplicate with a typical precision of $\sim 0.05 \%$ for elemental concentrations and $0.1 \%$ for $\delta^{13} \mathrm{C}_{\mathrm{TOC}}$. 
Phytolith Analysis

Phytolith analysis focuses on the preservation of the phytolith assemblages and their implication for the taphonomic history of the deposits.

\section{Phytolith Extraction}

Phytolith extraction followed the Katz et al. (2010) fast extraction procedure at the palynology laboratory of the Evolutionary Studies Institute, the University of the Witwatersrand. An initial sediment weight between 30 and $50 \mathrm{mg}$ was required. Carbonate minerals were dissolved adding $50 \mu \mathrm{l}$ of hydrochloric acid $(6 \mathrm{~N} \mathrm{HCl})$. Later, $450 \mu \mathrm{l}$ of $2.4 \mathrm{~g} / \mathrm{ml}$ sodium polytungstate solution $\left[\mathrm{Na} 6\left(\mathrm{H}_{2} \mathrm{~W}_{12} \mathrm{O}_{40}\right) \cdot \mathrm{H}_{2} \mathrm{O}\right]$ was added. The tube was vortexed, sonicated, and centrifuged for $5 \mathrm{~min}$ at $5000 \mathrm{rpm}$ (MiniSpin plus, Eppendorf). The supernatant was subsequently removed to a new $0.5-\mathrm{ml}$ centrifuge tube and vortexed. For examination under the optical microscope, an aliquot of $50 \mu \mathrm{l}$ of the supernatant was placed on a microscope slide and covered with a $24 \times$ 24-mm coverslip. Quantification of the total phytoliths present in $1 \mathrm{~g}$ of sediment was based on 20 fields of view at $\times 200$ magnification, whereas morphological identification of phytoliths took place at $\times 400$ magnification using an optical microscope (Olympus BX51). A minimum of 200 phytoliths was counted for the morphological analysis (Albert and Weiner 2001).

\section{Phytolith Classification}

Modern reference collections of South African plants (Cordova 2013; Cordova and Scott 2010; Esteban et al. 2017a; Murungi 2017; Murungi and Bamford 2020; Novello et al. 2018; Rossouw 2009) and modern surface soils (Cordova 2013; Cordova and Scott 2010; Esteban et al. 2017b; Novello et al. 2018) were used as comparative material for morphological identification and plant classification. Reference collections from other African regions have also been consulted (https://www. phytcore.org; Albert et al. 2016; Bamford et al. 2006; Barboni et al. 1999; Barboni and Bremond 2009; Collura and Neumann 2017; Mercader et al. 2009; Novello et al. 2012). Additionally, standard literature (Bozarth 1992; Mulholland and Rapp Jr. 1992; Piperno 2006; Twiss et al. 1969) was accessed. The terminology for describing phytolith morphotypes was based on the anatomical and taxonomic origin of the phytoliths.
When this was not possible, geometrical traits were followed. Descriptions and naming of the phytoliths follow the International Code for Phytolith Nomenclature 2.0 (ICPN 2.0; Neumann et al. 2019).

\section{Taphonomical Analysis}

To determine the degree of preservation of phytolith assemblages, correlation coefficients using the nonparametric Spearman's correlations and their $p$ value were calculated between the phytolith concentration per gram of sediment and four taphonomic indicators: (1) the percentage of weathered morphologies (i.e., phytoliths with signs of chemical dissolution; Esteban et al. 2018); (2) the percentage of fragile morphologies (Esteban et al. 2018, and references therein); (3) the diversity of the phytolith assemblage (number of morphotypes identified; Madella and Lancelotti 2012); and (4) the percentage of broken grass silica short cell phytoliths (GSSCPs) bilobate for each unit. This method measures the strength and direction of the association between two ranked variables (phytolith concentration and the taphonomic indicators). All statistical procedures were performed with the JMP SAS14.2.1 software.

\section{Cluster Analysis}

Visual inspection of the excavated sequence suggested patterns in the distribution of artifacts. For instance, there is a readily apparent higher find density in the lower layers. To objectively assess spatial patterns of varying density, statistical cluster analysis of the pieceplotted finds was undertaken using the HDBSCAN algorithm (Campello et al. 2013). HDBSCAN or Hierarchical Density-Based Spatial Clustering of Applications with Noise is a clustering algorithm that calculates for each point (i.e., a piece-plotted find) the minimum distance that is required to reach a set amount of other

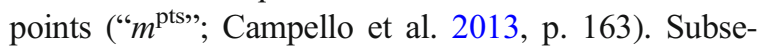
quently, the algorithm determines the mutual reachability distance, the distance required for two points to reach each other as well as the specified number of further points $\left(m^{\text {pts }}\right)$ needed to form a cluster. This, in turn, is used to define the minimum spanning tree, a network of points, connected through the minimum mutual reachability. HDBSCAN, therefore, defines spatial clusters and determines their stability throughout this process. In other words, clusters are defined as groups of points that are persistently interlinked. This algorithm employs 
only one user-defined input parameter (cf. DBSCAN; Ester et al. 1996) and OPTICS (Ankerst et al. 1999), namely the minimum amount of points needed to form a cluster ( $m^{\text {pts }}$; see below), and it can recognize clusters of complex shape and varying density. For this study, we used the density-based clustering toolset in ArcGIS Pro version 2.3.3 to apply the HDBSCAN algorithm on the three-dimensional point cloud of the piece-plotted finds. We used a consecutive series of $m^{\text {pts }}$ values of 2-20, 25, $30,50,100,200$, and 500 to scrutinize the changing clustering results.

\section{Results}

Stratigraphy and Sediments

We divided the deposits into two principal groups: the upper group $\mathrm{H}$, which corresponds to the Holocene deposits documented by Kaplan $(1989,1990)$, and group P (Pleistocene), below, characterized by defined stratigraphic boundaries and the presence of anthropogenic and biogenic features. The most prominent sources of anthropogenic sediments are in situ combustion features (Fig. 3), charcoal-rich stratigraphic layers, and ash/concreted ash layers. The color of the group $\mathrm{H}$ units ranges from dark to pale brown. In contrast, group $\mathrm{P}$ lacks discreet stratigraphic boundaries. We observe a few changes in sediment color and structure. Boundaries are gradual and difficult to pinpoint on the profile, and could not be accurately marked in our field drawings. One noticeable change in sediment color, a darker deposit, is present in the northern part of the profile, laterally bounding a lighter deposit (Fig. 3). This conforms to the disjunction between PBS and RBS identified by Kaplan (1990). These two sediment packages are distinguished by a change in moisture content; the darker sediments closer to the rockshelter wall are more humid than the lighter sediments located closer to the shelter's edge. Kaplan (1990, p. 4, 5) also reported the different moisture levels but did not connect these to the fact that the moisture level affects the color of the sediments. The color of the group $\mathrm{P}$ deposits ranges from brown and dark yellowish-brown to black in the high-moisture sediments.

The character of the group $\mathrm{P}$ sediments is not uniform, particularly in find density. To more reliably determine boundaries between high- and low-density units, we visually assessed the distribution of plotted finds and employed cluster analysis. The results led to the adjustment of unit boundaries, as well as the definition of a new lower-density unit P2. This unit was identified and described during the excavation, but its boundaries were not visible on the profile. Thus, it was not included in the initial stratigraphic drawing. Table 2 describes the stratigraphic units, and the synthesized stratigraphic assessment is discussed later in the article.

\section{Sediment Analysis}

\section{Particle Size Analysis}

Granulometry analysis shows that the entire sequence consists of sand to sandy loam (Fig. 5). Additional grain size parameters of selected samples are presented in Table 3. The particle size distributions are highly comparable throughout the sequence (Fig. 6). The total range of grain size values is between 100 and $550 \mu \mathrm{m}$. The sample average $(n=12)$ median particle size is $286 \mu \mathrm{m}$ or $1.8 \mathrm{Phi}(\sigma=18 \mu \mathrm{m})$. All of the samples are poorly sorted (mean sorting $1.8 \mathrm{Phi}$ or $297 \mu \mathrm{m}$ ) and negatively skewed (mean skewness -0.50 ). The Holocene sediments are marginally better sorted (1.59 Phi vs. 1.85 Phi; Mann-Whitney $U=4, p<0.05$ ) and possibly less negatively skewed (average -0.46 vs. -0.53 , nonsignificant) than the Pleistocene units. Particle size analysis of the rockshelter bedrock was not conducted because disaggregation was difficult to achieve in the laboratory. The typical grain sizes of the Natal sandstones range between 100 and $490 \mu \mathrm{m}$, with an average of $250 \mu \mathrm{m}$ (2 Phi) (Bell and Lindsay 1999). The Umhlatuzana sediments thus adhere closely to the grain size distribution of the bedrock (Fig. 6).

\section{pH Analysis}

$\mathrm{pH}$ values range from 4.6 to 9.1 (Table 2). These are weakly patterned throughout the sequence. The $\mathrm{pH}$ of the uppermost units (group H) is close to neutral, with values ranging from 7.2 to 7.6 . The values associated with combustion features have an alkaline $\mathrm{pH}$, ranging from 8.1 to 9.1 . The upper part of group P units (P1-P5) demonstrates nearly neutral $\mathrm{pH}$, with the average at 7.3. In the lower part of group $\mathrm{P}$, the $\mathrm{pH}$ values drop both in the higher and lower-moisture sediments (5.1 in higher-moisture unit P14 and 4.6 in lower-moisture unit P13). The average $\mathrm{pH}$ of the lowermost units (P12-P17) is 5.3. 
Fig. 5 Particle size analysis results, plotted to ternary texture diagram

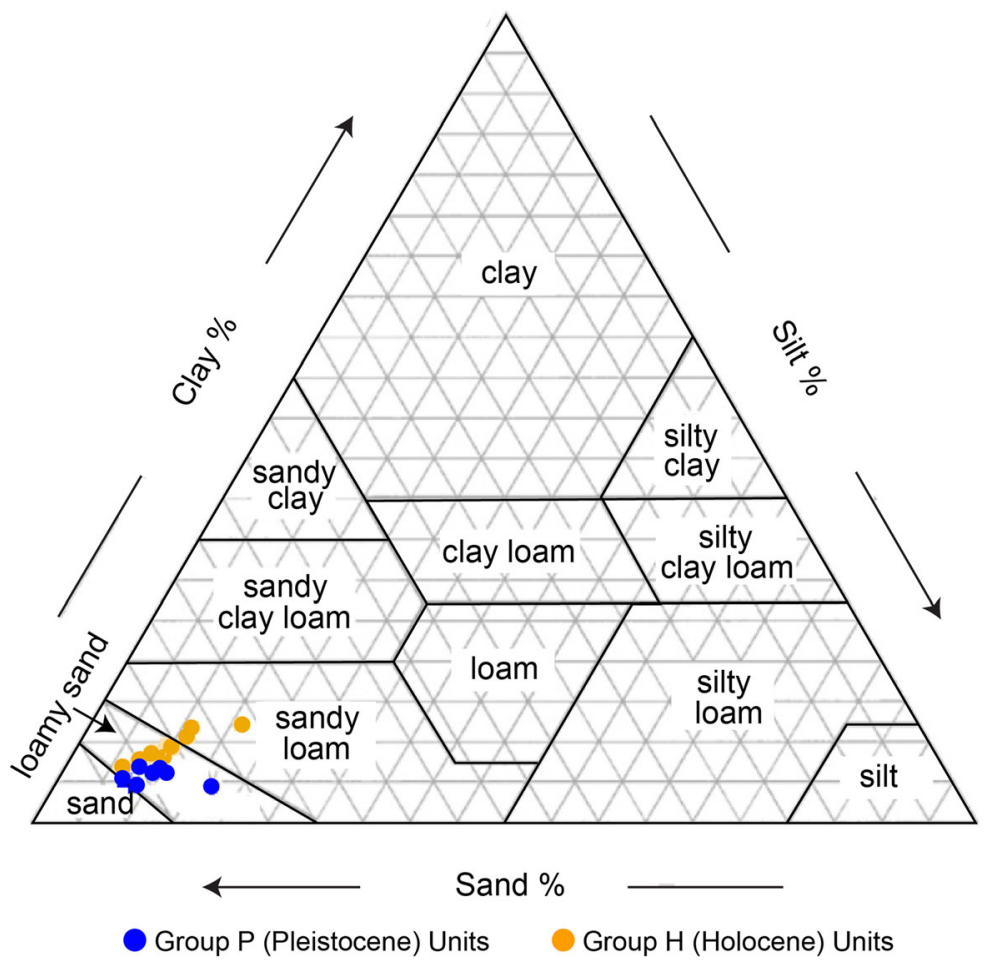

Organic Content Analysis

\section{FT-IR Analysis}

Our analysis shows that the overall mineralogical composition of the shelter's sediments is very homogeneous. The major mineralogical components of the 26 samples analyzed are clay (i.e., kaolinite) and quartz. Calcite (calcium carbonate), a common mineral in many archaeological sites, was virtually absent in the Pleistocene samples. The control samples collected from modern surface sediments, near the rockshelter, have traces of apatite, probably phosphate mineral carbonate hydroxylapatite (also called dahllite).
LOI results (Table 2) demonstrate the samples contain between 1.6 and $6.1 \%$ organic matter. The organic content demonstrates some patterning throughout the sequence. The uppermost surface layer (H1) contains the highest organic content, ranging from 4.1 to $6.1 \%$. The rest of the group $\mathrm{H}$ units average $3.5 \%$. A reduction in organic content is observed for stratigraphic units underlying the Pleistocene-Holocene boundary. These drop to $1.6 \%$ in unit $\mathrm{P} 1$ and gradually increase in the lower sequence. The average organic content for units
Fig. 6 Particle size distribution curves for selected representative samples, corresponding to units H1, H5, H9, H10, P1, P2, P4, P6, P7, P12, P14, and P17. Particle sizes are reported in a logarithmic scale. The mean grain size for the rockshelter (Natal sandstone) was derived by Bell and Lindsay (1999)

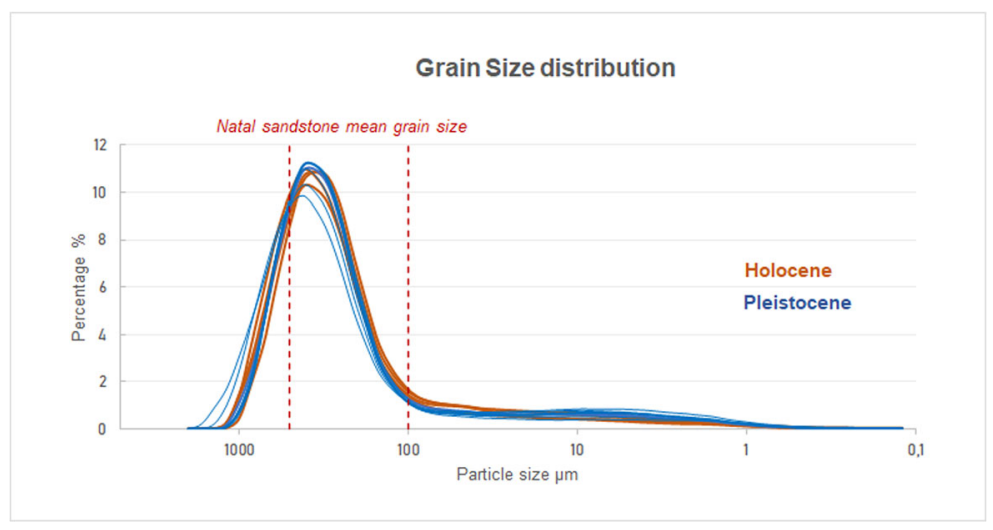


Fig. 7 Plot of phytolith content of the sediment samples (number of phytoliths/gram of sediments) and the percentage of weathered morphotypes per sample, illustrating the negative and statistically significant correlation between the two $(R,-0.468 ; p$, $0.0159)$
Weathered Morphotypes / Total Phytoliths

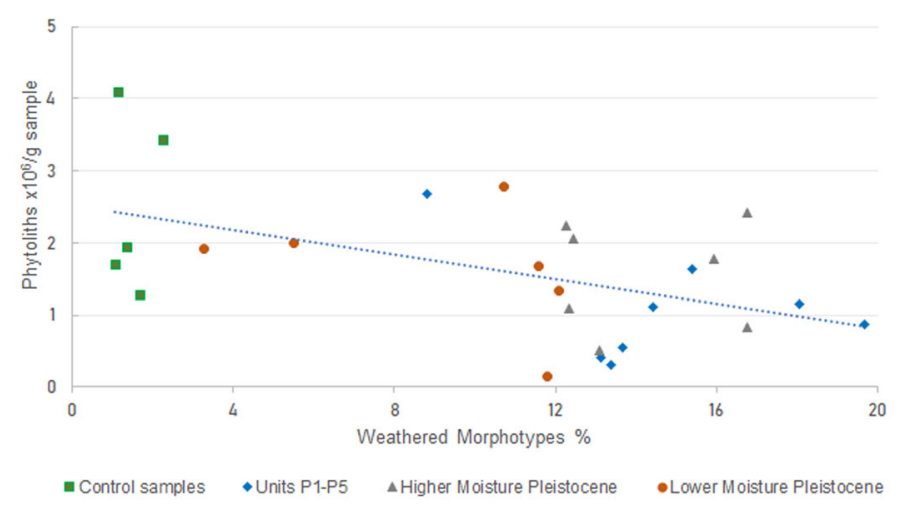

$\mathrm{P} 1-\mathrm{P} 5$ is $1.8 \%$. Organic content reaches $5.2 \%$ in unit $\mathrm{P} 13$. The average organic content for units P12-P17 is $4.1 \%$. No clear lateral patterning is observed.

\section{Elemental Analysis and Stable Carbon Isotope Analysis}

Total organic carbon (TOC) content confirms that the organic content is generally low, with $\sim 1 \%$ range through the sequence, spanning from $0.3 \%$ (unit P4) to $1.2 \%$ (units P9-P12). The lowest and least-varied TOC contents are seen for P3 to P4b (average $0.41 \%$ ). TOC content is higher for the lower units. This trend is also seen in the LOI results. TN is positively correlated ( $r=$ $0.70, p=<0.0001$ ) with TOC and tends to be higher (and more varied) values in units $\mathrm{P} 6$ and below. The average $\delta^{13} \mathrm{C}_{\mathrm{TOC}}$ values for units $\mathrm{P} 3-\mathrm{P} 4$ and $\mathrm{P} 5-\mathrm{P} 8$ are identical $(-22.2 \pm 0.4 \%$ o compared to $-22.5 \pm 0.4 \%$ o). Units P9P14 have a slightly more positive average value $(-21.8$ $\pm 0.6 \%$ ) but are also more varied and are not statistically different from units P3-P8. The Holocene samples H9b and $\mathrm{H} 10$ have markedly more negative $\delta^{13} \mathrm{C}_{\mathrm{TOC}}$ values $(-24 \pm 0.6 \%$ ) compared to the strikingly invariant group $P$ values (average $-22.1 \pm 0.7 \%$ ). Thus, the values for group $\mathrm{P}$ are more positive than the modern soils and sediments sampled around the site (average, $-26 \pm 2 \%$; $n=4$ ). We note that samples from within the closed woody $\left(\mathrm{C}_{3}\right)$ vegetation downslope of the rockshelter (i.e., samples $2-4 \delta^{13} \mathrm{C}_{\mathrm{TOC}}-26 \pm 1 \%$ ) are akin to the group $\mathrm{H}$ measurements, implying largely $\mathrm{C}_{3}$ vegetation inputs during the Holocene (Table 4).
Phytolith Analysis

All analyzed samples contained phytoliths in varying quantities, ranging from 148,000 (unit P8) to 2,780,000 (unit P8) phytoliths per gram of sediments (hereafter, /g sed) (Table 5). Control samples from the shelter surface had the highest phytolith concentrations, followed by the samples from unit P3, P8, and P5/P6. Control samples from modern soils outside the shelter are next in phytolith abundances. Three of the four examined taphonomic indicators showed no significant correlation with phytolith abundance. The exception is the proportion of weathered morphotypes, which showed a moderate negative correlation $\left(r^{2},-0.468 ; p\right.$ value, 0.0159$)$ with phytolith concentration (Fig. 7). This indicates that samples with lower phytolith concentrations contain a larger proportion of weathered morphotypes (Table 6). Nonsignificant correlations were found for the proportion of broken bilobates (weakly positive correlation; Table 6), the total number of morphotypes, and the percentage of fragile morphotypes (both moderately positive correlation; Table 6).

\section{Cluster Analysis}

The results of the cluster analysis indicate that four interfaces between dense and sparse zones of finds are significant. By using 2 or 3 as $m^{\text {pts }}$ values (i.e., very few finds required to form a cluster), the number of clusters exceeds 400 . Values from 4 to 9 yield a similar result in which nearly all the finds belong to one allencompassing cluster, but with small ( $<20$ finds) additional clusters located in the back of the excavated area. 

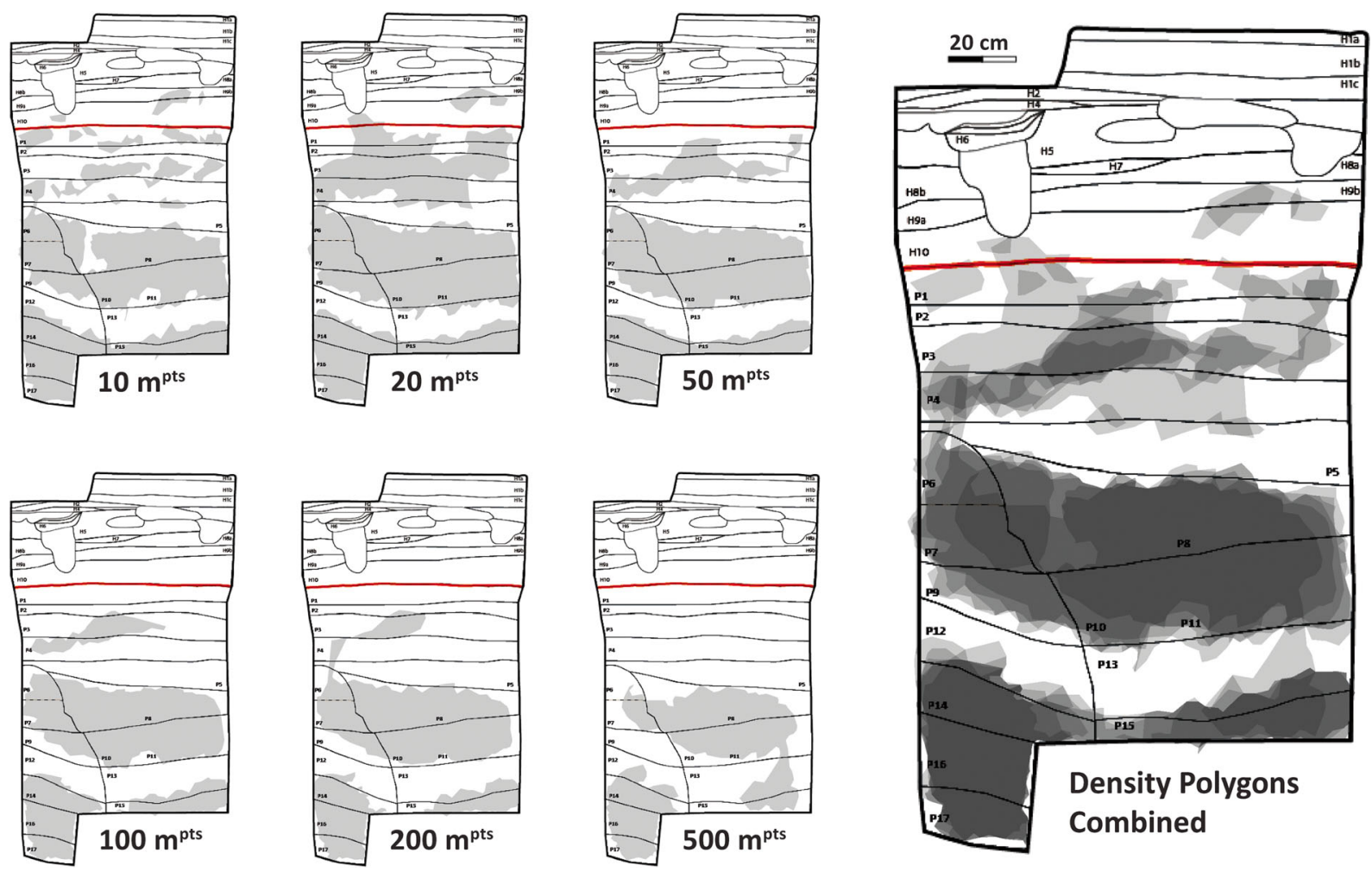

Fig. 8 Orthographic view of the clustering results using a value of 10, 20, 50, 100, 200, and 500 mpts: grey areas are clustered (left), and a combined view of these values, darker shades indicating areas which are most often considered clustered (right)

From an $m^{\mathrm{pts}}$ value of 10 onwards, the finds are persistently divided vertically into three dense areas, separated by sparse areas (Fig. 8). The uppermost dense area overlaps layers P1-P5; it disconnects into separate smaller pockets of high density at $m^{\text {pts }}$ value ranges beyond 14. This means the general area may be dense, but its individual pockets are poorly connected to one another. Within this, a less dense area visible mostly at $10 \mathrm{~m}^{\text {pts }}$ corresponds approximately to unit P2 (Fig. 8). Below it is a sparse wedge-shaped area, which ends abruptly at the top boundary of the second dense area. This dense area has sharply defined boundaries, overlaps units P6-P11, and is denser and far more homogeneous than the layers above. Below is the sparse but well-defined zone, units P12 and P13, followed by the third dense area (P14-P17), which is similar in characteristics to units P6-P11. The results suggest that the sediment below P5 is relatively undisturbed as they correspond to a reverse arch horizontal layering. The arching of the boundaries between dense and sparse zones is more pronounced in the bottom, and less so in the top, perhaps illustrating the topology of the sedimentary surfaces. The more heterogeneous appearance of the higher located dense area may be the result of postdepositional disturbance through, for example, animal burrowing.

\section{Stratigraphic Synthesis}

Figure 9 shows the synthesis of the stratigraphy of the western profile based on the results of the above analyses. Due to unclear stratigraphic boundaries in the Pleistocene sequence, piece-plotted measurements of finds were employed to distinguish high- and low-density stratigraphic units. The stratigraphic units from both groups $\mathrm{H}$ and $\mathrm{P}$ demonstrate horizontal layering. A more detailed description of the two groups, starting from the youngest to the oldest, follows below.

\section{Group H-the Holocene}

This group of units coincides with the sequence that Kaplan (1990) dated to the Holocene. 
Fig. 9 Stratigraphic drawing of the western profile exposed in squares L3a, L2b, and L2a. On the right: selected calibrated radiocarbon (black) and OSL (red) ages in years BP (Kaplan 1990, Lombard et al. 2010).

Group H (Holocene) unit subdivisions are based on lithostratigraphic characteristics of the layers. Group P

(Pleistocene) unit subdivisions are based on a combination of lithostratigraphic characteristics and find density mapping

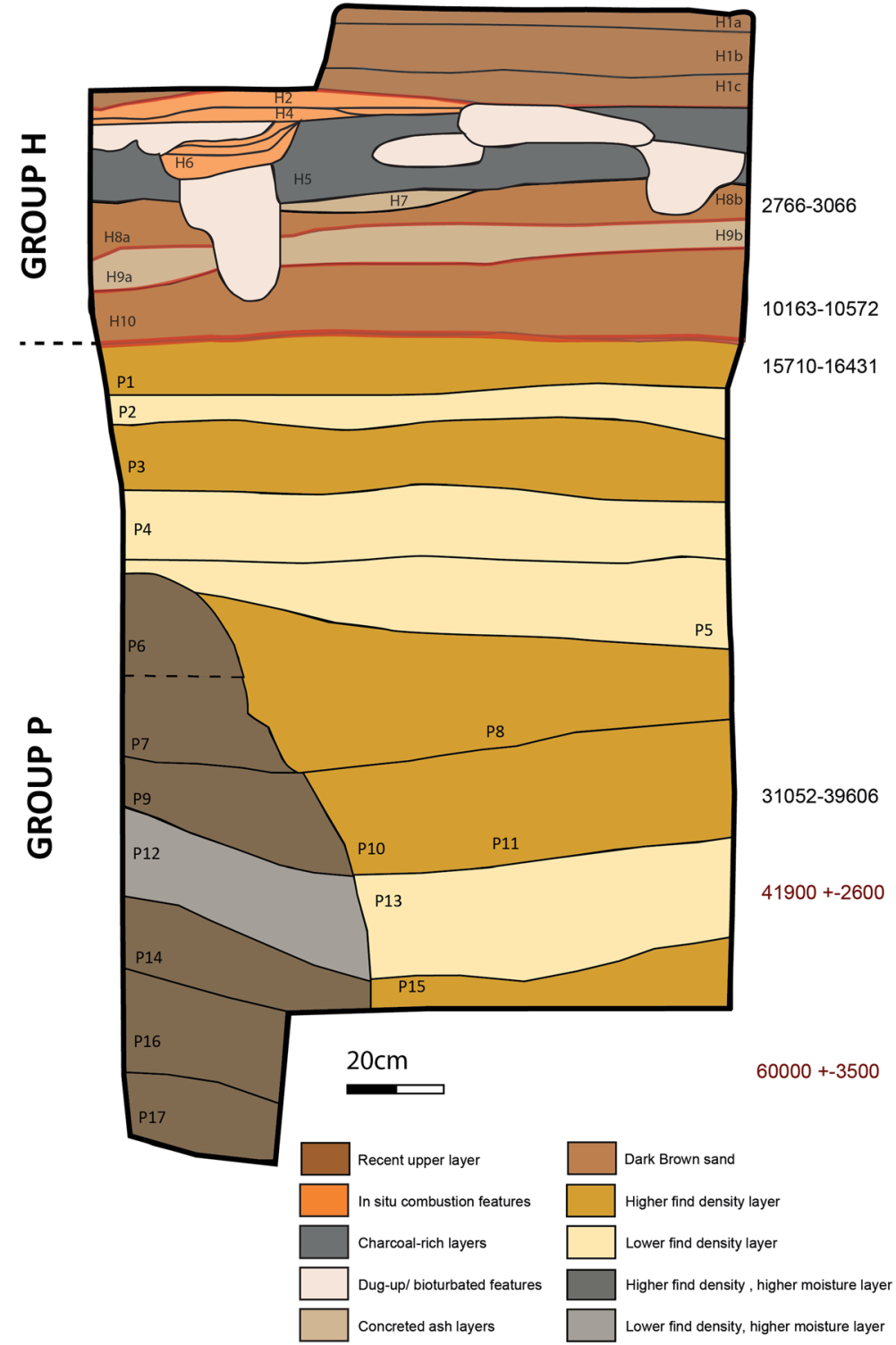

- The uppermost surface deposit (unit H1) is a darkbrown sand layer that covers the entire excavation area and has a total thickness of $\sim 20 \mathrm{~cm}$. Three distinct facies can be recognized within the unit, namely H1a, H1b, and H1c. Facies H1b is characterized by the presence of white, millimeter-sized, and probably calcitic inclusions. Leaves and roots are found within unit H1, indicating a very recent age.

- Underlying unit H1, a hearth/combustion feature (H2-H4) extends across most of the west and north profiles. The boundary between units $\mathrm{H} 1$ and $\mathrm{H} 2$ is sharp and clear. The hearth consists of three layers, from top to bottom: unit H2, a yellowish-gray ash layer; unit H3, a black layer; and unit H4, a darkbrown layer. Heated bone is abundant in ash-rich unit H2. This layering is typical of in situ combustion features with a white uppermost layer of ash, a black layer characterized by heated organic material, and a lowermost red/brown layer of rubified sediment (Mentzer 2014). The contacts between the three hearth layers are sharp and partially bioturbated by insect burrows (likely ant lions, currently present at the site) (Fig. 3). 
Table 1 Currently available radiometric ages from Umhlatuzana. Radiocarbon dates from Kaplan (1990) were recalibrated in OxCal (Bronk Ramsey 1995) using the southern hemisphere calibration curve (SHCal 13; Hogg et al. 2013). OSL ages from Lombard et al. (2010). All radiocarbon dates reported at $95 \%$ probability range of the calibration

\begin{tabular}{|c|c|c|c|c|c|}
\hline Lab number & Depth cm & Age BP & Calibrated age & $\begin{array}{l}\text { Stratigraphic context } \\
\text { (Kaplan 1990) }\end{array}$ & $\begin{array}{l}\text { Stratigraphic context } \\
\text { current analysis }\end{array}$ \\
\hline Pta-4215 & 44 & $2,840 \pm 60$ & $3,066-2,766$ & FBSA, layer 3 & H8/H9b \\
\hline Pta-4307 & 60 & $9,180 \pm 90$ & $10,572-10,163$ & OBSA, layer 4 & H10 \\
\hline \multicolumn{6}{|c|}{ High moisture } \\
\hline Pta-4389 & 132 & $27,800 \pm 780$ & $33,700-30,795$ & PBS spit 3 III, layer 15 & P6 \\
\hline Pta-4663 & 156 & $35,300 \pm 930$ & $41,905-38,094$ & PBS spit VI, layer 18 & P7 \\
\hline Pta-4665 & 164 & $38,200 \pm 1100$ & $44,530-40,705$ & PBS spit VIII, layer 20 & P9 \\
\hline Pta-4666 & 180 & $37,100 \pm 1100$ & $43,451-39,510$ & PBS spit IX, layer 21 & $\mathrm{P} 9 / \mathrm{P} 12$ \\
\hline Pta-4234 & 196 & $45,200+3200 /-5400$ & $\infty-42,717$ & PBS spit XI, level 23 & P14 \\
\hline \multicolumn{6}{|l|}{ Low moisture } \\
\hline Pta-4226 & 68 & $13,400 \pm 120$ & $16,431-15,710$ & RBSA, layer 5 & $\mathrm{H} 10 / \mathrm{P} 1$ \\
\hline Pta-4228 & 156 & $30,100 \pm 1,800$ & $39,606-31,052$ & RBS spit XIII, layer 17 & P11 \\
\hline Pta-4331 & 164 & $35,100 \pm 830$ & $41,676-38,338$ & RBS spit XIV, layer 18 & P11 \\
\hline Pta-4288 & 184 & $34,400 \pm 1,000$ & $41,190-36,500$ & RBS spit XVI, layer 20 & P13 \\
\hline Pta-4235 & 184 & $35,000 \pm 1,600$ & $42,911-36,151$ & RBS spit XVI, layer 20 & $\mathrm{P} 13$ \\
\hline Pta-4366 & 184 & $37,100 \pm 1,100$ & $43,451-38,510$ & RBS spit XVI, layer 20 & $\mathrm{P} 13$ \\
\hline Pta-4333 & 184 & $40,600 \pm 1,500$ & $47,848-42,155$ & RBS spit XVI, layer 20 & P13 \\
\hline \multicolumn{6}{|l|}{ OSL } \\
\hline UMH 4 & 180 & $41,900 \pm 2,600$ & & RBS spit XVI, layer 20 & P13 \\
\hline UMH 5 & 215 & $60,000 \pm 3,500$ & & RBS spit XX, layer 22 & Unexcavated \\
\hline UMH 6 & 252 & $70,500 \pm 4,700$ & & RBS spit XXIII, layer 25 & Unexcavated \\
\hline
\end{tabular}

- A dark-brown loamy sand, unit H5, underlies the hearth feature. It is characterized by poorly sorted charcoal remains that comprise around $5 \%$ of the deposit. Unit $\mathrm{H} 5$ extends throughout the excavation area and has a thickness of 10-20 cm. In some areas, unit H1 directly overlies unit H5. Several dug-out and bioturbation features are present within unit $\mathrm{H} 5$.

- A second hearth feature (unit H6) is articulated within unit H5. Animal burrows are visible in it, and it consists of three smaller layers. The uppermost unit H6a is a light-gray ash layer, a coarse dark-brown layer (H6b) underlies H6a, and the bottom layer (H6c) is characterized by a dull-orange sediment color. Animal burrows were visible within these layers. Compared to the $\mathrm{H} 2-\mathrm{H} 3-\mathrm{H} 4$ hearth, H6 is a smaller-scale hearth feature with around $4 \mathrm{~cm}$ thickness and $20 \mathrm{~cm}$ width.

- Unit H7 underlies unit H5; the contact between them is clear, abrupt, and bioturbated with visible smallscale tunneling. Unit $\mathrm{H} 7$ is an indurated ash layer with a dull-brown color and thickness of $\sim 5 \mathrm{~cm}$.
- Unit H8 is a brownish-black loamy sand layer. It underlies unit $\mathrm{H} 5$, and the boundary between them is gradual and bioturbated. The thickness ranges between 5 and $15 \mathrm{~cm}$. Unit H8 contains very few charcoal and bone inclusions randomly distributed. At a corresponding depth, Kaplan (1990) obtained a Late Holocene radiocarbon date (see Table 1) from the unit he called fine brown sand with ash, likely corresponding to our unit $\mathrm{H} 8$.

- Unit H9 is a layer of distinct aggregates of finegrained material, moderately cemented for the most part, and often loose and friable. The boundaries between unit $\mathrm{H} 9$ and both overlying unit $\mathrm{H} 8$ and underlying unit $\mathrm{H} 10$ are sharp, irregular, and discrete. The color of unit $\mathrm{H} 9$ is dull yellow-orange, and its thickness ranges from 5 to $12 \mathrm{~cm}$. Unit $\mathrm{H} 9$ spans much of the excavated area and can be found throughout the western, northern, and part of the eastern profiles. It is also characterized by the presence of heated bone fragments. 
Table 2 Stratigraphic units of Umhlatuzana. Field description (color, strength, plasticity, stickiness) of the stratigraphic units defined in our current research and their corresponding lab analysis results (particle size analysis, $\mathrm{pH}$, loss on ignition)

\begin{tabular}{|c|c|c|c|c|c|c|c|c|}
\hline Unit & Munsell (light) & Munsell (shade) & Strength & Plasticity & Stickiness & Texture & $\mathrm{pH}$ & Organic content $\%$ \\
\hline $\mathrm{H} 1 \mathrm{a}$ & $10 Y R 3 / 4$ & $10 Y R 3 / 3$ & $\square$ & $\bullet$ & $\bullet$ & Loamy sand & 7.2 & 4.1 \\
\hline $\mathrm{H} 1 \mathrm{~b}$ & & & & & & Sand & 7.3 & 6.1 \\
\hline $\mathrm{H} 1 \mathrm{c}$ & & & & & & Sand & 7.6 & 4.6 \\
\hline $\mathrm{H} 2$ & $10 \mathrm{YR} 4 / 2$ & $10 Y R 4 / 3$ & $\square$ & ০ & ০০০ & & & \\
\hline $\mathrm{H} 3$ & $10 \mathrm{YR} 2 / 2$ & 10YR 2/1 & $\hookrightarrow$ & ০০০ & ০০০ & & & \\
\hline $\mathrm{H} 4$ & $10 \mathrm{YR} 2 / 3$ & $10 \mathrm{YR} 3 / 4$ & $\square \square$ & $\bullet \bullet$ & $\circ \bullet$ & & & \\
\hline H5 & $10 Y R 3 / 4$ & $10 Y R 3 / 3$ & $\square$ & $\circ$ & 000 & Loamy sand & 8.1 & 3.9 \\
\hline H6a & 5YR 8/1 & $5 Y R \quad 8 / 2$ & & & & & & \\
\hline $\mathrm{H} 6 \mathrm{~b}$ & $7.5 \mathrm{YR} 3 / 3$ & 7.5YR 3/4 & & & & & & \\
\hline H6c & $5 Y R 6 / 3$ & $5 Y R 6 / 3$ & & & & & & \\
\hline $\mathrm{H} 7$ & 7.5 YR $5 / 3$ & 7.5YR 5/3 & घ & ০০০ & $\circ \bullet$ & & & \\
\hline $\mathrm{H} 8 \mathrm{a}$ & $10 Y R 2 / 3$ & $10 Y R 2 / 2$ & $\square \square$ & ০০০ & ০০০ & Loamy sand & 9.1 & 3.4 \\
\hline $\mathrm{H} 8 \mathrm{~b}$ & $10 Y R 2 / 2$ & $10 Y R 2 / 3$ & $\square \square$ & $\circ \bullet$ & $\circ \bullet$ & Loamy sand & 9.1 & 3.4 \\
\hline $\mathrm{H} 9 \mathrm{a}$ & $10 Y R 6 / 3$ & $10 \mathrm{YR} 6 / 3$ & 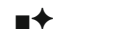 & $\bullet$ & $\bullet$ & Sand & 8.9 & 3.4 \\
\hline $\mathrm{H} 9 \mathrm{~b}$ & 10YR 6/3 & $10 \mathrm{YR} 6 / 3$ & 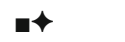 & $\bullet$ & $\bullet$ & Sand & 8.9 & 3.4 \\
\hline $\mathrm{H} 10$ & $10 \mathrm{YR} 3 / 3$ & 10YR 3/4 & $\square \square$ & $\circ \bullet$ & $\circ \bullet$ & Loamy sand & 8.9 & 2.7 \\
\hline $\mathrm{P} 1$ & $10 \mathrm{YR} 2 / 3$ & $10 \mathrm{YR} 2 / 3$ & $\square \square$ & ০০ & ০০০ & Loamy sand & 7.3 & 1.6 \\
\hline $\mathrm{P} 2$ & $10 \mathrm{YR} 2 / 3$ & $10 \mathrm{YR} 2 / 3$ & $\square \square$ & $\circ \bullet$ & ০০০ & Loamy sand & 7.2 & 1.9 \\
\hline P3 & $10 Y R 3 / 4$ & $10 \mathrm{YR} 3 / 4$ & $\square$ & ০০০ & ০০ & Sandy loam & 7.6 & 1.9 \\
\hline P4 & $10 \mathrm{YR} 3 / 3$ & 10YR 3/4 & घ & $\circ \bullet$ & ০০০ & Loamy sand & 7.1 & 2.1 \\
\hline P5 & 10YR 3/4 & $10 Y R 3 / 4$ & $\square \square$ & ০০০ & ০০০ & Loamy sand & 7.5 & 1.8 \\
\hline P6 & $10 Y R 3 / 3$ & $10 \mathrm{YR} 3 / 4$ & $\square$ & ০ & $\bullet$ & Loamy sand & 6.5 & 2.8 \\
\hline P7 & 10YR 1.7/1 & 10YR 1.7/1 & $\square \square$ & $\bullet$ & $\bullet$ & Loamy sand & 6.2 & 3.6 \\
\hline P8 & $10 \mathrm{YR} 3 / 3$ & 10YR 3/4 & $\square \square$ & ০০০ & ০০০ & Loamy sand & 7.0 & 1.9 \\
\hline P9 & $5 Y R 3 / 2$ & $5 Y R 2 / 2$ & $\square$ & 000 & ০০০ & & & \\
\hline $\mathrm{P} 10$ & $7.5 \mathrm{YR} 3 / 3$ & 7.5YR 3/4 & $\square$ & $\circ \bullet$ & $\circ \bullet$ & Loamy sand & 6.2 & 3.1 \\
\hline P11 & $10 Y R 4 / 3$ & $10 \mathrm{YR} 4 / 3$ & घ & ০০০ & ০০০ & Sandy loam & 6.0 & 3.2 \\
\hline $\mathrm{P} 12$ & $5 Y R 3 / 2$ & $5 Y R 2 / 2$ & $\square \square$ & ০০০ & ০০০ & Loamy sand & 5.7 & 4.0 \\
\hline P13 & $7.5 \mathrm{YR} 3 / 3$ & 7.5 YR $3 / 4$ & $\square$ & $\circ \bullet$ & $\circ \bullet$ & Loamy sand & 4.6 & 5.2 \\
\hline P14 & $5 Y R 3 / 3$ & $5 Y R 3 / 2$ & $\square$ & $\bullet$ & $\bullet$ & Sand & 5.1 & 4.4 \\
\hline $\mathrm{P} 15$ & 10YR 5/4 & $10 \mathrm{YR} 4 / 4$ & $\square \square$ & $\bullet$ & ০০০ & Sandy loam & 5.7 & 3.8 \\
\hline P16 & $5 Y R 3 / 3$ & $5 Y R 3 / 2$ & $\square \square$ & $\bullet$ & $\bullet$ & & & \\
\hline P17 & $10 Y R 3 / 3$ & $10 \mathrm{YR} 2 / 2$ & $\square \square$ & ০০০ & ০০০ & Loamy sand & 5.5 & 3.0 \\
\hline
\end{tabular}

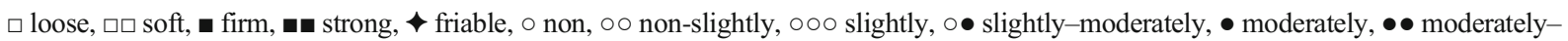
very

- The lowermost unit of the Holocene layers is unit H10. The boundaries of unit H10 are sharp and discrete with both unit $\mathrm{H} 9$ and Pleistocene unit P1. The color of the sediments is dark brown, and its thickness reaches up to $20 \mathrm{~cm}$. Unit $\mathrm{H} 10$ contains both charcoal and bone inclusions but at a low frequency. An early Holocene radiocarbon date (Table 1) was obtained by Kaplan (1990) from what he described as the orange-brown sand with ash level. This level possibly corresponds to our unit H10.

\section{Holocene-Pleistocene Boundary}

The boundary between the group $\mathrm{H}$ and the group $\mathrm{P}$ deposits is clear and well-defined on the stratigraphic 
Table 3 Particle size parameters of selected representative samples. Following Folk and Ward (1957) moment statistics

\begin{tabular}{|c|c|c|c|c|c|c|c|c|c|c|c|c|}
\hline & H1 & H5 & H9 & H10 & $\mathrm{P} 1$ & $\mathrm{P} 2$ & $\mathrm{P} 4$ & P6 & P7 & P12 & P14 & P17 \\
\hline Mean & 266 & 211 & 245 & 214 & 228 & 171 & 185 & 225 & 197 & 239 & 292 & 195 \\
\hline Median & 303 & 262 & 282 & 281 & 283 & 263 & 276 & 284 & 284 & 283 & 326 & 308 \\
\hline Sorting & 350 & 323 & 367 & 295 & 307 & 249 & 257 & 298 & 266 & 316 & 310 & 227 \\
\hline Skew & -0.4 & -0.5 & -0.4 & -0.5 & -0.5 & -0.6 & -0.6 & -0.5 & -0.6 & -0.5 & -0.4 & -0.6 \\
\hline Kurtosis & 1.9 & 1.9 & 1.8 & 1.8 & 2.1 & 1.9 & 2.0 & 2.2 & 2.0 & 2.2 & 2.1 & 1.9 \\
\hline
\end{tabular}

unit: microns

Table 4 Bulk elemental analysis results. Notable within the data is the intersample $\delta^{13} \mathrm{C}_{\mathrm{TOC}}$ variability for unit $\mathrm{P} 4$, which is as large as the total range seen for all samples in group P. Modern surface samples were taken from the following contexts: surface 1: finegrained sediment (unvegetated) within the rockshelter, west of excavation, immediately below the edge of the overhang; surface 2, 3: modern soils $\sim 3$ and $6 \mathrm{~m}$ (respectively) downslope from the rockshelter within dense, woody vegetation; surface 4: modern soil, well-vegetated $\sim 25 \mathrm{~m}$ east of the rockshelter at the top of the valley slope (more open than surface 2 and 3 )

\begin{tabular}{|c|c|c|c|c|}
\hline Unit & Total nitrogen $(\%)$ & Total carbon $(\%)$ & Total organic carbon $(\%)$ & $\delta^{13} \mathrm{C}$ TOC \\
\hline \multicolumn{5}{|l|}{$S q . L 3 a$} \\
\hline P3 & 0.05 & 0.50 & 0.44 & -21.8 \\
\hline $\mathrm{P} 3$ & 0.06 & 0.46 & 0.46 & -22.0 \\
\hline $\mathrm{P} 3$ & 0.05 & 0.43 & 0.46 & -22.3 \\
\hline P5 & 0.03 & 0.58 & 0.53 & -23.3 \\
\hline P6 & 0.08 & 0.89 & 0.70 & -22.7 \\
\hline P6 & 0.09 & 1.21 & 0.87 & -22.2 \\
\hline $\mathrm{P} 7$ & 0.09 & 1.12 & 0.85 & -21.9 \\
\hline $\mathrm{P} 7$ & 0.10 & 1.54 & 0.55 & -22.6 \\
\hline $\mathrm{P} 9 / 12$ & 0.11 & 1.93 & 0.96 & -21.6 \\
\hline $\mathrm{P} 9 / 12$ & 0.11 & 1.57 & 1.29 & -22.0 \\
\hline P14 & 0.10 & 1.35 & 0.96 & -22.1 \\
\hline \multicolumn{5}{|c|}{$S q . L 2 b, L 2 a$} \\
\hline $\mathrm{H} 9 \mathrm{~b}$ & 0.06 & 3.11 & 0.44 & -24.5 \\
\hline $\mathrm{H} 10$ & 0.09 & 1.16 & 0.88 & -23.6 \\
\hline $\mathrm{P} 4 \mathrm{~b}$ & 0.05 & 0.55 & 0.31 & -20.0 \\
\hline $\mathrm{P} 4 \mathrm{~b}$ & 0.05 & 0.68 & 0.44 & -21.8 \\
\hline $\mathrm{P} 4 \mathrm{~b}$ & 0.07 & 0.57 & 0.33 & -23.6 \\
\hline $\mathrm{P} 4 \mathrm{a}$ & 0.05 & 0.58 & 0.45 & -22.2 \\
\hline $\mathrm{P} 4 \mathrm{a}$ & 0.05 & 0.50 & 0.27 & -22.8 \\
\hline P5 & 0.04 & 0.55 & 0.48 & -22.2 \\
\hline P8 & 0.07 & 0.54 & 0.45 & -22.2 \\
\hline P8 & 0.06 & 0.73 & 0.64 & -22.6 \\
\hline $\mathrm{P} 11$ & 0.07 & 0.81 & 0.46 & -20.6 \\
\hline $\mathrm{P} 11$ & 0.07 & 0.92 & 0.76 & -22.3 \\
\hline P11 & 0.07 & 0.94 & 0.81 & -22.0 \\
\hline Surface 1 & 0.10 & not determined & 1.16 & -22.5 \\
\hline Surface 2 & 0.37 & not determined & 5.02 & -27.4 \\
\hline Surface 3 & 0.31 & not determined & 0.90 & -27.1 \\
\hline Surface 4 & 0.19 & not determined & 1.67 & -24.8 \\
\hline
\end{tabular}


Table 5 Phytolith results. List of analyzed samples giving sample provenance, concentration, percentage of weathered morphotypes, percentage of broken bilobates, number of morphotypes identified, and percentage of fragile morphotypes

\begin{tabular}{|c|c|c|c|c|c|c|}
\hline Unit & Square & Phytoliths/g sed & $\%$ Weathered morphotypes & $\%$ Broken bilobate & \# Morphotypes & $\%$ Fragile morphotypes \\
\hline P1 & L3a & 408,461 & 13.12 & 26.26 & 20 & 4.60 \\
\hline P3 & L3a & $2,684,169$ & 8.81 & 27.27 & 20 & 11.86 \\
\hline P3 & L3a & 309,112 & 13.39 & 37.59 & 23 & 5.27 \\
\hline $\mathrm{P} 3$ and $\mathrm{P} 4 \mathrm{a}$ & L3a & $1,123,815$ & 14.42 & 31.17 & 22 & 5.73 \\
\hline $\mathrm{P} 4 \mathrm{a}$ & L3a & 868,747 & 19.68 & 23.20 & 19 & 3.29 \\
\hline $\mathrm{P} 4 \mathrm{a}$ & L3a & $1,639,232$ & 15.38 & 47.17 & 19 & 7.58 \\
\hline $\mathrm{P} 5$ and P6 & L3a & $2,424,411$ & 16.77 & 54.76 & 19 & 2.88 \\
\hline P6 & L3a & $1,775,015$ & 15.93 & 31.87 & 22 & 6.19 \\
\hline $\mathrm{P} 4 \mathrm{~b}$ & $\mathrm{~L} 2 \mathrm{~b}$ & 542,302 & 13.67 & 36.67 & 22 & 4.58 \\
\hline P5 & $\mathrm{L} 2 \mathrm{~b}$ & $1,160,465$ & 18.06 & 33.33 & 22 & 6.07 \\
\hline P6 & L3a & $2,239,623$ & 12.25 & 34.62 & 23 & 6.49 \\
\hline P7 & L3a & 503,065 & 13.10 & 9.09 & 20 & 4.35 \\
\hline P7 & L3a & $1,097,255$ & 12.34 & 37.93 & 20 & 2.96 \\
\hline P8 & $\mathrm{L} 2 \mathrm{~b}$ & 148,302 & 11.79 & 33.77 & 18 & 5.50 \\
\hline P8 & $\mathrm{L} 2 \mathrm{~b}$ & $1,333,426$ & 12.09 & 38.24 & 17 & 8.72 \\
\hline P8 & $\mathrm{L} 2 \mathrm{~b}$ & $1,670,878$ & 11.59 & 34.62 & 20 & 5.74 \\
\hline P8 & $\mathrm{L} 2 \mathrm{~b}$ & $2,786,117$ & 10.73 & 40.63 & 20 & 1.78 \\
\hline P11 & $\mathrm{L} 2 \mathrm{~b}$ & $1,915,285$ & 3.29 & 41.26 & 18 & 7.28 \\
\hline P11 & $\mathrm{L} 2 \mathrm{~b}$ & $1,990,310$ & 5.52 & 28.36 & 17 & 10.90 \\
\hline P9 & L3a & $2,054,015$ & 12.44 & 25.55 & 25 & 6.05 \\
\hline $\mathrm{P} 9$ and P12 & L3a & 824,582 & 16.75 & 26.56 & 22 & 11.27 \\
\hline Control sample & & $4,077,528$ & 1.14 & 19.66 & 30 & 19.65 \\
\hline Control sample & & $3,426,289$ & 2.27 & 22.77 & 30 & 12.99 \\
\hline Soil sample & & $1,276,741$ & 1.71 & 39.81 & 22 & 6.61 \\
\hline Soil sample & & $1,934,602$ & 1.37 & 43.53 & 27 & 1.39 \\
\hline Soil sample & & $1,688,278$ & 1.08 & 35.00 & 27 & 5.47 \\
\hline
\end{tabular}

Table 6 Phytolith taphonomic indicators. Spearman's correlation coefficients $(R)$ and the $p$ value computation of the phytolith concentration per gram of sediment against (a) percentage of weathered morphologies, (b) percentage of fragile morphologies, and (c) number of phytolith morphotypes and percentage of broken bilobates

\begin{tabular}{|c|c|c|c|c|}
\hline Variable 1 & Variable 2 & Spearman $\rho$ & Prob $>|\rho|$ & Interpretation \\
\hline Weathered & Phytoliths/g sed & -0.468 & 0.0159 & Moderate dissolution \\
\hline Broken bilobate & Phytoliths/g sed & 0.0506 & 0.8061 & No correlation \\
\hline Broken bilobate & Weathered & -0.0725 & 0.7249 & No correlation \\
\hline \# Morphotypes & Phytoliths/g sed & 0.2419 & 0.2338 & Low dissolution \\
\hline \# Morphotypes & Weathered & -0.2391 & 0.2393 & Low dissolution \\
\hline \# Morphotypes & Broken bilobate & -0.2551 & 0.2084 & Moderate dissolution \\
\hline Fragile morphotypes & Phytoliths/g sed & 0.3402 & 0.0891 & Moderate dissolution \\
\hline Fragile morphotypes & Weathered & -0.2485 & 0.2208 & Low dissolution \\
\hline Fragile morphotypes & Broken bilobate & -0.3177 & 0.1138 & Moderate dissolution \\
\hline Fragile morphotypes & \# Morphotypes & 0.0686 & 0.7391 & No correlation \\
\hline
\end{tabular}


profile (Fig. 3). This was also clearly observed by the initial excavator (Kaplan 1990) who obtained a radiocarbon date of 10,379 $\pm 104 \mathrm{cal} \mathrm{BP}$ (Pta-4307) from his layer 4, corresponding to our unit H10, while the underlying layer 5 in Kaplan's original work (our unit P1) yielded a date of $16,326 \pm 439 \mathrm{cal}$ BP (Pta-4226). All of this suggest a hiatus in sedimentation between group $\mathrm{H}$ and group P deposits (Kaplan 1990; Lombard et al. 2010).

The Holocene and the Pleistocene deposits contrast in several other aspects. The find density for the Holocene deposits is low, as shown in the find distribution plots (Fig. 8). Grain size analysis suggests different texture patterns within the two groups, with a slightly higher percentage of clay for the Pleistocene deposits (Fig. 5). Moreover, the results of $\mathrm{pH}$ and LOI indicate a clear pattern between the two groups (Fig. 10). Group H deposits are characterized by higher $\mathrm{pH}$ and lower organic matter values, while group $\mathrm{P}$ has lower $\mathrm{pH}$-higher organic matter values. A difference between group $\mathrm{H}$ and group $\mathrm{P}$ deposits is also implied by the $\delta^{13} \mathrm{C}_{\mathrm{TOC}}$ results (Table 4).

Group P-the Pleistocene

This group of stratigraphic units dates to the Late Pleistocene (Kaplan 1990).

- The uppermost unit is P1, brownish-black loamy sand. It has a thickness of $\sim 12 \mathrm{~cm}$ and is characterized by a high density of finds. Patches of orange sediments were observed during the excavation. This unit corresponds to the red-brown sand with ash in the original excavation. A radiocarbon date of terminal Pleistocene age was obtained at this depth (Table 1; Kaplan 1990).

- Unit P2 is very similar to P1. The contact between them is not visible in the profile, and this unit was not initially drawn in the field sketch. Its different sedimentological characteristics became clear during excavation. Unit P2 is $5-10$ $\mathrm{cm}$ thick and characterized by a low find density. The sediment of P2 is more compact than P1 and the underlying unit P3. Data from the find density plots were used to specify the location of this layer for the final stratigraphic drawing.

- Unit P3 is a dark-brown layer with a width varying from 16 to $18 \mathrm{~cm}$. It is characterized by a higher density of finds and the presence of a few heavily weathered bone fragments.

- Unit P4 underlies P3 with a gradual and smooth boundary. It has a dark-brown color, and the thickness is $15-18 \mathrm{~cm}$. The unit is firmer compared to unit $\mathrm{P} 3$ and has a lower find density.

- Unit P5 is also a low find density unit. The boundary with P4 is vague and was not clearly visible in the field. The sediments of unit P5 have a dark-brown color; its thickness varies greatly from $5 \mathrm{~cm}$ in the southern part to $20 \mathrm{~cm}$ in the northern part. Unit P4 is firmer than P5, which is also characterized by the presence of many modern rootlets.

Underneath unit P5, a lateral color difference was observed, mirroring the RBS and PBS highlighted by Kaplan (1990). The sediments on the south side of the profile appear darker in color and clearly contained more moisture, while the sediments on the north side were lighter and drier. The boundary between the dark and light sediments was diffuse. A discrete color difference was recorded in the field (i.e., P7: 10YR1,7/1 black, P8: 10YR3/3 dark brown). However, when dried, the colors were more alike (P7: 10YR4/3 dull yellowishbrown, P8: 10YR5/4 dull yellowish-brown).

- Unit P6 underlies unit P5 on the south side (high moisture). The sediment is loose and contains a high density of finds and a total thickness of around $20 \mathrm{~cm}$. This unit likely corresponds to the purplebrown sands observed by Kaplan (1990). A radiocarbon date of $27,800 \pm 780$ BP (Pta-4389) was obtained at a corresponding depth (Kaplan 1990).

- Unit P7 is black loamy sand with a high density of finds. It has a thickness of $18 \mathrm{~cm}$ and underlies unit P6. The exact location of their contact is not clearly visible, but the sediments in P7 are softer and darker in color.

- On the northern side of the west profile, unit P8 is dark brown with a high find density. With thickness that is $18-32 \mathrm{~cm}$ thick, P8 underlies unit P5, is laterally adjacent to units P6 and P7, and overlies units P10 and P11. None of its contacts with the surrounding units were clearly visible in the profile.

- P9 underlies unit P7. It is located in the south, highmoisture area, and has a thickness of $15-21 \mathrm{~cm}$. It is characterized by a high find density and a dark reddish-black color. 
Fig. 10 Graph illustrating a clear patterning between the lower $\mathrm{pH}-$ higher organic content Pleistocene units vs. the higher $\mathrm{pH}-$ lower organic content Holocene units

\section{$\mathrm{pH} /$ Organic Content distribution}

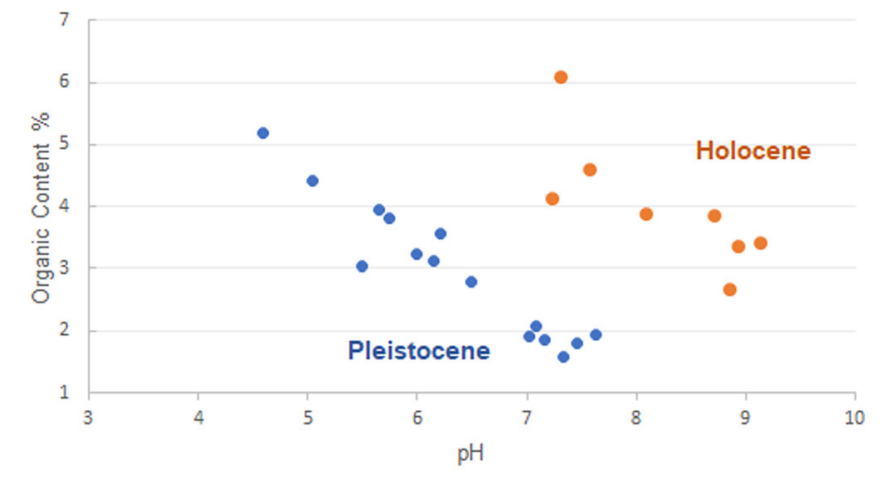

- Unit P10 has a relatively lower moisture content than P9 and also has a high find density. It underlies unit $\mathrm{P} 8$ and is laterally differentiated from unit $\mathrm{P} 9$ to the south and from unit P11 to the north. Unit P11 is a dull yellowish-brown sandy loam with a high find density. Units P10 and P11 are both around 20-25 $\mathrm{cm}$ thick. They are distinguished by sediment characteristics: unit P10 is softer compared to the firmer sediments of P11. A radiocarbon age of $30,100 \pm$ 1,800 BP (Pta-4228) was obtained at a corresponding depth from Red Brown Sands XIII (Kaplan 1990).

- Unit P12 has high moisture content and a low find density. The thickness ranges from 15 to $18 \mathrm{~cm}$. It is adjacent to unit $\mathrm{P} 13$, which is characterized by lower moisture, loamy sand of 18-20 cm thickness, and a low find density. The boundaries of units P12 and P13 with their surrounding units are diffuse. Unit P13 corresponds to Kaplan's Red Brown Sands XVI from which a suite of radiocarbon dates with calibrated ages between 39,000 BP and 44,000 BP (Kaplan 1990) and an OSL age of 42,000 $\pm 3,000$ BP (Lombard et al. 2010) were obtained.

- Unit P14 is approximately $15 \mathrm{~cm}$ thick, underlying unit P13. It is characterized by dark reddish-black sand with a high find density. The contact between units $\mathrm{P} 14$ and $\mathrm{P} 13$ dips by $\sim 20^{\circ}$ to the north and is diffuse.

- Unit P15 has a high find density and is laterally adjacent to P14 and below unit P13. The lower contact of unit 15 has not been excavated; its maximum exposed thickness is $15 \mathrm{~cm}$ in the north part of square L2A.
- The high-density unit P16 consists of dark reddishblack sands of $20 \mathrm{~cm}$ thickness, and underlying unit P14. During excavation, white, centimeter-sized inclusions with a fibrous structure were observed in the south part of square L3a. Analogous to other sites, they are interpreted as gypsum deposits (cf. Pickering 2006). FT-IR and micromorphology analyses of these deepest layers will be undertaken to confirm this. At a corresponding depth in the Red Brown Sands, not reached in our excavations, an OSL age of $60,000 \pm 4,000 \mathrm{BP}$ was obtained (Lombard et al. 2010).

- The lowermost exposed unit is P17 and had a very high find density, especially on the lower part (contact with bedrock). It underlies unit P16 and has a thickness of $17 \mathrm{~cm}$.

- The lower parts of the Pleistocene sequence (units P14-P17) were suggested to represent lag deposits because of their sometimes very high find density (Kaplan 1990, 12). However, no clear indications for erosional events or truncations were observed in the sequence.

Archaeological Observations

The Holocene sediments yielded both Iron Age and Later Stone Age material culture (Kaplan 1989). The find density was relatively low compared to much of the Pleistocene sequence. A few pieces of thickwalled, undecorated pottery, which can be placed in the late Iron Age (Whitelaw pers. comm.), derive from unit H1. After sorting sieved sediments, small 
Achatina beads $(\sim 3 \mathrm{~mm}$ diameter $)$ were recovered from this unit. The lowermost $\mathrm{H}$ units contain Later Stone Age lithic assemblages. Retouched tools are rare; a preliminary scan of the material yielded one scraper fragment from unit $\mathrm{H} 5$ and one thumbnail scraper from unit H9. No segments were observed. The dates obtained by Kaplan (1990) and the absence of backed segments are consistent with the attribution of these lowermost $\mathrm{H}$ units to the final Later Stone Age (Lombard et al. 2012). Both units $\mathrm{H} 10$ and P1 yield bladelets. Larger artifacts such as blades and a convergent scraper were observed. This is in line with earlier collections Kaplan (1990, p. 41-44) attributed to the late Robberg. A number of piece-plotted bone fragments were also recovered from unit $\mathrm{H} 10$.

In unit $\mathrm{P} 1$, bone preservation was much poorer, and only a few severely weathered bones were observed. Units P3-P5 yielded materials consistent with the assemblages attributed to the early Robberg (Kaplan 1990). Bladelets and bladelet cores were recovered, but larger pieces such as large flakes and a few blades were also present. No large retouched artifacts were observed. Unit P6 yielded both bladelets and characteristic MSA forms, including a hollow-based point (cf. Mohapi 2013). In unit P8, laterally to the south of unit P6, a similar mix of bladelets and MSA elements such as large blades and a unifacial point was observed. Unit P8 also yielded a number of backed segments. A scan of the lithic materials suggests unit P7 contains a more typical MSA assemblage with unifacial points and has a noteworthy presence of large debitage products and backed segments. Bladelets, although rare, were also recovered.

Kaplan (1989) notes the presence of segments in the Late MSA and MSA/LSA transition layers but states that their presence increases in the Howiesons Poort assemblages. In our excavations, unit P11 yielded a large number of segments. This unit corresponds to the Late MSA described by Kaplan. Segments were also recovered in substantial numbers from deeper units P15 and P16. These correspond to the Howiesons Poort layers from Kaplan's (1990) excavations. The lowermost unit P17, directly above bedrock in square L3a, yielded a broken part of a point, bifacially worked with a serrated edge. This fits with previously described Still Bay materials from the site (Lombard et al. 2010; Högberg and Lombard 2016a).

\section{Discussion}

Our renewed excavations confirm many of the observations previously made by Kaplan $(1989,1990)$ and Lombard et al. (2010). That is, Umhlatuzana contains a clearly defined Holocene sequence that contrasts with homogenous Pleistocene deposits that are characterized by diffuse stratigraphic boundaries. The site also preserves a long MSA and LSA occupation history. We demonstrate that the absence of visible stratigraphic indicators does not mean that a stratigraphic subdivision cannot be made. Field observations indicate differences in the physical characteristics of the sediment (i.e., strength and plasticity) across the sequence. We supplement these sediment characteristics with an analysis of find density to arrive at stratigraphic subdivisions. This approach parallels that taken at the nearby site of Umbeli Belli, where the Pleistocene sediments are also largely undifferentiated (Bader et al. 2018, p. 734).

The granulometric analysis shows a homogeneous sediment composition throughout the sequence, characterized as loamy sand. This composition closely matches the grain size distribution of the Natal sandstones (Fig. 6; Bell and Lindsay 1999), suggesting a mostly closed depositional environment in which geogenic inputs mainly originate from in situ weathering of the rockshelter sandstones. This may partly account for the gradual and diffuse stratigraphic boundaries. Important in situ weathering input is also seen at other sites, such as Pinnacle Point 5-6 (Karkanas et al. 2015) and Mwulu's Cave (de la Peña et al. 2019).

There are no indications for aeolian, fluvial, or gravity flow sediments introduced into the sequence. Fluvial inputs were not expected as the river level is $80-100 \mathrm{~m}$ downhill. Sheetwash processes from surrounding slopes also appear absent as the fine bedding produced in such sedimentary regimes was not observed. Aeolian sediments are characteristically well-sorted; their presence would have resulted in the second peak of fine-grained sediments (see de la Peña et al. 2019). The sediments are consistently poorly sorted and negatively skewed (fine tail) and show a single peak (Fig. 6). The absence of other sedimentological input results in a homogeneous matrix with an essentially identical texture and composition throughout the sequence. In comparison to nearby sites such as Umbeli Belli, angular roof spall is not abundant (Bader et al. 2018). No clast-supported layers were present, and the matrix overwhelmingly consists of loamy sand throughout the sequence. The FT-IR results 
also indicate the homogeneity of the group P deposits, confirming the granulometry results. The presence of apatite in the two control samples from the shelter's surface is likely the result of recent human activities. The present-day use of the area for overnight shelter was observed during fieldwork by the presence of hearths with food remains and makeshift tents.

Organic artifact preservation is poor in the Pleistocene sediments. Bone remains in Pleistocene deposits were poorly preserved and scarce $(n=239$ out of a total of 8,210 measured finds in the Pleistocene). A few bone fragments located in square L2a, unit P11, appear to be unweathered, implying that postdepositional processes did not affect the whole sequence equally. The organic content of the sediments is higher in the Holocene deposits (average $3.88 \%$ ), is lower in the upper part of the Pleistocene sequence (average 1.83\%), and then increases again in the lower part of the Pleistocene sequence (average 3.98\%). The elemental analysis (comparison of the carbon content of acid-treated vs. untreated samples) reveals that most of the carbon content of the sediments is organic. This confirms FT-IR data showing carbonates to be (largely) absent. The relatively low organic contents of the site's sediments implied by the LOI analysis are mirrored by the low overall TOC content. The rather invariant TOC (also sometimes reported as \% C) contrasts with sediments of other South African rockshelters, some of which show far greater variability (e.g., Collins et al. 2017; Loftus et al. 2015; Roberts et al. 2013).

The $\mathrm{pH}$ values range from 9.1 within combustion features in the Holocene deposits, to as low as 4.6 in the Pleistocene deposits. This is a high variation in comparison to the other rockshelters of similar geoarchaeological contexts (the type of bedrock, climatic conditions, time span, etc.). For example, Gledswood Shelter 1, a rockshelter developed in a sandstone bedrock with $\mathrm{a} \sim 2.5 \mathrm{~m}$ Pleistocene occupation sequence, has a much lower degree of $\mathrm{pH}$ value variation, ranging from 5 to 5.5 (Lowe et al. 2016). The $\mathrm{pH}$ results of Umhlatuzana raise two questions: what caused the variation of the $\mathrm{pH}$ values and how are they related to preservation conditions throughout the sequence? One possibility is that the $\mathrm{pH}$ values are influenced by the variant moisture content within the sediments (e.g., higher- vs. lower-moisture layers). Regarding the preservation conditions, there is indeed a connection between high $\mathrm{pH}$ values and better bone preservation at the Holocene layers and poor bone preservation and lower $\mathrm{pH}$ values in the Pleistocene. However, for nonosseous organic matter, the reverse relationship holds. Especially in the Pleistocene, the $\mathrm{pH}$ and LOI are negatively correlated in strong and statistically significant terms $(r,-0.95 ; p<0.01)$, and the Holocene layers show a similar, but less significant correlation $(r$, $-0.77 ; p, 0.02$ ) (Fig. 10). A more systematic sampling strategy in the future is projected to shed more light on the exact trend.

The modern soils immediately outside the shelter contained lower phytolith densities than some of the archaeological sediments. This supports an anthropogenic origin of the archaeological phytolith assemblage. Phytolith preservation is good in relatively acidic conditions (e.g., Piperno 1988), and here they are wellrepresented in the Pleistocene deposits. Samples with high and low phytolith concentrations are present in both the low- and the high-find density layers. The presence of up to $20 \%$ weathered morphotypes in some samples indicates chemical alterations did affect the phytolith assemblage and led to the partial dissolution in some samples. The taphonomical analysis suggests that although phytoliths underwent partial dissolution, it was not extensive enough to affect the whole dataset. Therefore, the phytolith assemblage at Umhlatuzana partially represents the initial plant composition. The anomalously high presence of broken bilobates in some samples is intriguing. One explanation is that these are the result of episodes of trampling.

Discrete high- and low-find density zones were observed in the field and confirmed by cluster analysis of the piece-plotted finds. These zones cross-cut the boundary between high-moisture sediments (PBS sensu Kaplan 1990) on the south side of the trench and low-moisture sediments (RBS) on the north side, suggesting that no sediment slump or rotational slip took place. A Kruskal-Wallis test shows phytolith content does not differ significantly between high-moisture and low-moisture sediments $(H, 0.007 ; p, 0.94)$. However, a comparison of the percentage of weathered morphotypes shows that there is a significant difference between the samples from the dark and wet deposits (PBS) compared to those from the dry deposits on the north side of the profile $(H, 9 ; p<0.01)$. The samples from the dark sediments appear to be more weathered, possibly due to the higher moisture content.

Cluster analysis identified three main high density find zones, separated by zones of low-find density (roughly corresponding to P4/P5 and P12/P13, Fig. 8). 
The lower two dense areas and the sparse zone that separates them indicate a stable trench-wide sedimentation environment. The wedge-shaped zone between the middle and upper dense areas agrees with the impression of trench-wide stability, but its sloped upper and lower boundaries suggest that the stratigraphy cannot be perceived as absolutely level layers of archaeological material. This should be critically considered when studying the archaeological material from the original excavation as they were collected in horizontal spits. Additionally, the finds in the dense upper area are less homogeneously distributed. Cluster analysis indicates that either the depositional processes for these layers were less stable or postdepositional processes disturbed a layered initial deposit.

The different high- and low-find density layers may reflect periods of higher and lower intensity of human occupation, but they could have also resulted from lower and higher sedimentation rates (cf. Reynard et al. 2016). On current evidence, the upper low-find density zone may be explained most parsimoniously by an increased sedimentation rate (compare ages and depths in Table 1 and Fig. 1). On average, the phytolith content of the lowest units is higher than that of the upper part of the Pleistocene sequence (note that no phytolith data are currently available for the lowermost units). As phytolith input is likely anthropogenic, this could suggest that occupation intensity decreased in the upper units. This hypothesis will be assessed in the future with new dating results and micromorphological analysis.

A preliminary typological analysis of the artifacts mirrors the interpretations of Kaplan (1989, 1990). In the 2018/2019 excavations, the lowermost layers were only reached in square L3A. These yielded a bifacially worked serrated piece fragment, in line with previously described Still Bay materials from the site (Lombard et al. 2010; Högberg and Lombard 2016b). Segments are present throughout the Middle Stone Age sediments, occurring from units P16 and P15 to unit P7. We have also recovered a variety of unifacial points, mainly in units P11-P8. Some of these are hollow-based points, and similar artifacts have been recovered at Sibudu (Mohapi 2012). The artifacts in the youngest MSA deposits at nearby Umbeli Belli yielded abundant bifacial points (Bader et al. 2016, 2018). In contrast, we did not recover bifacial points in the uppermost MSA deposits.

\section{Conclusions}

The objective of the renewed excavations at Umhlatuzana was to understand the site's depositional history and to establish the integrity of the Pleistocene lithic assemblages. Our results confirm previous observations, such as the presence of Still Bay, Howiesons Poort, and Robberg materials, as well as LSA and Iron Age material culture in the uppermost levels. However, our stratigraphic analysis shows that the disjunction between dark and light sediments in the MSA deposits resulted from differences in moisture content and is not related to large-scale sediment movement. The fact that higher moisture levels occur closer to the rockshelter walls suggests that the moisture could be maintained by minor water flow from the bedrock sandstones to the deposits. Visual inspection of piece-plotted finds combined with cluster analysis suggests the shelter surface was near-horizontal throughout most of the site's depositional history. This means that the assemblages collected in artificial spits during the previous excavations do not represent severe chronologically mixed lithic collections.

Geochemical and FTIR analyses confirm the poor preservation conditions for organic material and the largely homogenous composition of the sediments. The low-pH environment is possibly connected to the paucity of faunal remains in the Pleistocene sequence. The apparent absence of combustion features in the Pleistocene deposits is surprising. At nearby sites of comparable age like Sibudu, they are abundant. It appears unlikely that the lack of such features reflects the absence of fire use at the site. The absence of combustion features is likely due to the postdepositional destruction of traces of fire. This may have had the added effect of removing visible stratigraphic layering. A combination of sediment homogenizing bioturbation activities and the effects of changing hydrology may have caused postdepositional alterations. This is consistent with the mostly homogenous geochemistry and sedimentology of the site (e.g., $\delta^{13} \mathrm{C}_{\mathrm{TOC}}$, lithology).

The exclusion of large-scale sediment movement demonstrates that the intermediate character of the MSA/LSA transition assemblages recovered from the site is not the result of postdepositional mixing of MSA and LSA materials. The virtual absence of sloping in the piece-plotted high- and low-density zones also confirms that assemblages recovered in horizontal artificial spits do not cross-cut original depositional surfaces and can be studied as internally consistent assemblages. 
Micromorphological and geochemical analyses are planned in the future to further address the preservation conditions across the archaeological sequence. Additional OSL dating will be undertaken to improve the chronological resolution of the sequence, as well as to analyze the character and prevalence of small-scale sedimentary mixing events.

Acknowledgments We thank Donald Davies, Jan Dekker, Barbara Dunn, Guus Halewijn, Geeske Langejans, Ghilraen Laue, Vumani Madinani, Femke Reidsma, Len van Schalkwyk, Amon Sokela, Chris Thornhill, and Carolyn Thorp for assistance in the field. We are also grateful to the KwaZulu-Natal Museum, Department of Human Sciences, Geoff Blundell, Phumulani Madonda, Mudzunga Munzhedzi, Dimakatso Tlhoalele, and Gavin Whitelaw for the support. We received valuable assistance from the Netherlands State Service for Heritage, Hans Huisman, and Mario van IJzendoorn. We gratefully acknowledge AMAFA aKwaZulu-Natali, SAHRA, Bernadet Pawandiwa, and Sumeri Uys for issuing the requisite permits. We thank Femke Reidsma for assisting with the $\mathrm{pH}$ analysis and interpretation, and Morgan Roussel for helping with the French abstract. Facilities for the LOI and grain size analyses were provided by the Vrije Universiteit Amsterdam with the assistance of Martine Hagen and Maarten Prins. I. Esteban and M. Murungi acknowledge the DSI-NRF Centre of Excellence in Palaeosciences. Finally, we want to thank three anonymous reviewers and the editing team for the helpful comments on an earlier version of this paper.

Funding This research is funded by NWO Vidi-grant 276-60004, awarded to Gerrit Dusseldorp.

\section{Compliance with Ethical Standards}

Conflict of Interest The authors declare that they have no conflict of interest.

Open Access This article is licensed under a Creative Commons Attribution 4.0 International License, which permits use, sharing, adaptation, distribution and reproduction in any medium or format, as long as you give appropriate credit to the original author(s) and the source, provide a link to the Creative Commons licence, and indicate if changes were made. The images or other third party material in this article are included in the article's Creative Commons licence, unless indicated otherwise in a credit line to the material. If material is not included in the article's Creative Commons licence and your intended use is not permitted by statutory regulation or exceeds the permitted use, you will need to obtain permission directly from the copyright holder. To view a copy of this licence, visit http://creativecommons.org/licenses/by/4.0/.

\section{References}

Albert, R. M., \& Weiner, S. (2001). Study of phytoliths in prehistoric ash layers from Kebara and Tabun caves using a quantitative approach. In J. D. Meunier \& F. Colin (Eds.), Phytoliths: Applications in earth sciences and human history (pp. 251-266). Lisse: Balkema Press.

Albert, R. M., Ruíz, J. A., \& Sans, A. (2016). PhytCore ODB: A new tool to improve efficiency in the management and exchange of information on phytoliths. Journal of Archaeological Science, 68, 98-105. https://doi.org/10.1016 /J.JAS.2015.10.014.

Ambrose, S. H. (1986). Stable carbon and nitrogen isotope analysis of human and animal diet in Africa. Journal of Human Evolution, 15, 707-731. https://doi.org/10.1016/S0047-2484 (86)80006-9.

Anderson, G. (2014). Rehabilitation of Umhlatuzana rock shelter, KwaZulu-Natal. Meerensee: Report by Umlando Cultural Heritage for AMAFA KwaZulu-Natal.

Ankerst, M., Breunig, M. M., Kriegel, H. P., \& Sander, J. (1999). Optics: Ordering points to identify the clustering structure. SIGMOD Record, 28, 49-60.

Archer, W., Pop, C. M., Gunz, P., \& McPherron, S. P. (2016). What is Still Bay? Human biogeography and bifacial point variability. Journal of Human Evolution, 97, 58-72.

Backwell, L., d'Errico, F., \& Wadley, L. (2008). Middle Stone Age bone tools from the Howiesons Poort layers, Sibudu Cave, South Africa. Journal of Archaeological Science, 35, 15661580.

Backwell, L. R., d'Errico, F., Banks, W. E., de la Peña, P., Sievers, C., Stratford, D., Lennox, S. J., Wojcieszak, M., Bordy, E. M., Bradfield, J., \& Wadley, L. (2018). New excavations at Border Cave, KwaZulu-Natal, South Africa. Journal of Field Archaeology, 43(6), 417-436.

Bader, G. D., Cable, C., Lentfer, C., \& Conard, N. J. (2016). Umbeli Belli Rock Shelter, a forgotten piece from the puzzle of the Middle Stone Age in KwaZulu-Natal, South Africa. Journal of Archaeological Science: Reports, 9, 608-622.

Bader, G. D., Tribolo, C., \& Conard, N. J. (2018). A return to Umbeli Belli: New insights of recent excavations and implications for the final MSA of eastern South Africa. Journal of Archaeological Science: Reports, 21, 733-757.

Bader, G. D., Lindstädter, J., \& Schoeman, M. H. (2020). Uncovering the Late Pleistocene LSA of Mpumalanga Province, South Africa: Early results from Iron Pig Rock Shelter. Journal of African Archaeology, 18(1), 19-37.

Bamford, M. K., Albert, R. M., \& Cabanes, D. (2006). PlioPleistocene macroplant fossil remains and phytoliths from Lowermost Bed II in the eastern palaeolake margin of Olduvai Gorge, Tanzania. Quaternary International, 148, 95-112. https://doi.org/10.1016/j.quaint.2005.11.027.

Barboni, D., \& Bremond, L. (2009). Phytoliths of East African grasses: An assessment of their environmental and taxonomic significance based on floristic data. Review of Palaeobotany and Palynology, 158, 29-41. https://doi.org/10.1016/j. revpalbo.2009.07.002.

Barboni, D., Bonnefille, R., Alexandre, A., \& Meunier, J. D. (1999). Phytoliths as paleoenvironmental indicators, West Side Middle Awash Valley, Ethiopia. Palaeogeography, Palaeoclimatology, Palaeoecology, 152, 87-100. 
Bell, F. G., \& Lindsay, P. (1999). The petrographic and geomechanical properties of some sandstones from the newspaper member of the Natal Group near Durban, South Africa. Engineering Geology, 53, 57-81. https://doi.org/10.1016 /S0013-7952(98)00081-7.

Bertran, P., \& Texier, J. P. (1995). Fabric analysis: Application to paleolithic sites. Journal of Archaeological Science, 22, 521535. https://doi.org/10.1006/jasc.1995.0050.

Bozarth, S. R. (1992). Classification of opal phytoliths formed in selected dicotyledons native to the Great Plains. In J. G. Rapp \& C. S. Mulholland (Eds.), Phytolith systematics. Emerging issues, advances in archaeological and museum science (pp. 193-214). New York: Plenum Press.

Bronk Ramsey, C. (1995). Radiocarbon calibration and analysis of stratigraphy: The OxCal program. Radiocarbon, 37, 425430.

Campello, R. J. G. B., Moulavi, D., \& Sander, J. (2013). Densitybased clustering based on hierarchical density estimates. In J. Pei, V. S. Tseng, L. Cao, H. Motoda, \& G. Xu (Eds.), Advances in knowledge discovery and data mining (pp. 160-172). Berlin: Springer.

Collins, J. A., Carr, A. S., Schefuß, E., Boom, A., \& Sealy, J. (2017). Investigation of organic matter and biomarkers from Diepkloof Rockshelter: Insights into Middle Stone Age site usage and palaeoclimate. Journal of Archaeological Science, $85,51-65$.

Collura, L. V., \& Neumann, K. (2017). Wood and bark phytoliths of West African woody plants. Quaternary International, 434, 142-159. https://doi.org/10.1016/j.quaint.2015.12.070.

Conard, N. J., Porraz, G., \& Wadley, L. (2012). What is in a name? Characterising the 'post-Howieson's Poort' at Sibudu. South African Archaeological Bulletin, 67, 180-199.

Cordova, C. E. (2013). C3 Poaceae and restionaceae phytoliths as potential proxies for reconstructing winter rainfall in South Africa. Quaternary International, 287, 121-140. https://doi. org/10.1016/j.quaint.2012.04.022.

Cordova, C. E., \& Scott, L. (2010). The potential of Poaceae, Cyperaceae and Restionaceae phytoliths to reflect past environmental conditions in South Africa. In J. Runge (Ed.), African palaeoenvironments and geomorphic landscape evolution (pp. 107-134). Abingdon: Taylor \& Francis.

Deacon, J. (1984). The Later Stone Age of southernmost Africa, Oxford: British Archaeological Reports International Series 213.

Deacon, H. J., \& Deacon, J. (1999). Human beginnings in South Africa: Uncovering the secrets of the Stone Age. Cape Town: D. Phillip.

d'Errico, F., Backwell, L., Villa, P., Degano, I., Lucejko, J. J., Bamford, M. K., Higham, T. F. G., Colombini, M. P., \& Beaumont, P. B. (2012). Early evidence of San material culture represented by organic artifacts from Border Cave, South Africa. Proceedings of the National Academy of Sciences, 109, 13214-13219.

Dusseldorp, G. L. (2012). Tracking the influence of Middle Stone Age technological change on modern human hunting strategies. Quaternary International, 270, 70-79.

Erlanger, E., Granger, D., \& Gibbon, R. (2009). Uplift rates of southern Africa from incision of the Sundays River, South Africa. AGU Fall Meeting Abstracts, 2155.

Esteban, I., Vlok, J. H. J., Kotina, E. L., Bamford, M. K., Cowling, R. M., Cabanes, D., \& Albert, R. M. (2017a). Phytoliths in plants from the south coast of the Greater Cape Floristic Region (South Africa). Review of Palaeobotany and Palynology, 245, 69-84. https://doi.org/10.1016/j. revpalbo.2017.05.001.

Esteban, I., De Vynck, J. C., Singels, E., Vlok, J. H. J., Marean, C. W., Cowling, R. M., Fisher, E. C., Cabanes, D., \& Albert, R. M. (2017b). Modern soil phytolith assemblages used as proxies for Paleoscape reconstruction on the south coast of South Africa. Quaternary International, 434, 160-179. https://doi.org/10.1016/j.quaint.2016.01.037.

Esteban, I., Marean, C. W., Fisher, E. C., Karkanas, P., Cabanes, D., \& Albert, R. M. (2018). Phytoliths as an indicator of early modern human plant gathering strategies, fire fuel and site occupation intensity during the Middle Stone Age at Pinnacle Point 5-6 (south coast, South Africa). PLOS ONE, 13(6), e0198558. https://doi.org/10.1371/journal.pone.0198558.

Ester, M., Kriegel, H. P., Sander, J., \& Xu, X. (1996). A densitybased algorithm for discovering clusters in large spatial databases with noise. In E. Simoudis, J. Han, \& U. Fayyad (Eds.), Proceedings international conference on knowledge discovery and data mining (pp. 226-231). Menlo Park: AAAI Press.

Fisher, E. C., Cawthra, H. C., Esteban, I., Jerardino, A., Neumann, F. H., Oertle, A., Pargeter, J., Saktura, R., Szabó, K., Winkler, S., \& Zohar, I. (2020). Coastal occupation and foraging during the last glacial maximum andearly Holocene at Waterfall Bluff, eastern Pondoland, South Africa. Quaternary Research. https://doi.org/10.1017 /qua.2020.26.

Folk, R. L., \& Ward, W. C. (1957). A study in the significance of grain-size parameters. Journal of Sedimentary Petrology, 27, 3-26. https://doi.org/10.1306/74D70646-2B21-11D7$8648000102 \mathrm{C} 1865 \mathrm{D}$.

Garrison, E. G. (2003). Techniques in archaeological geology (2nd ed.). Berlin: Springer. https://doi.org/10.1007/978-3319-30232-4.

Goldberg, P., \& Macphail, R. (2006). Practical and theoretical geoarchaeology. Oxford: Blackwell Publishing. https://doi. org/10.1002/gea.20248.

Goldberg, P., Miller, C. E., Schiegl, S., Ligouis, B., Berna, F., Conard, N. J., \& Wadley, L. (2009). Bedding, hearths, and site maintenance in the Middle Stone Age of Sibudu Cave, KwaZulu-Natal, South Africa. Archaeological and Anthropological Sciences, 1(2), 95-122.

Haaland, M. M., Friesem, D. E., Miller, C. E., \& Henshilwood, C. S. (2017). Heat-induced alteration of glauconitic minerals in the Middle Stone Age levels of Blombos Cave, South Africa: Implications for evaluating site structure and burning events. Journal of Archaeological Science, 86, 81-100.

Henshilwood, C. S. (2012). Late Pleistocene techno-traditions in southern Africa: A review of the Still Bay and Howiesons Poort, c. 75-59 ka. Journal of World Prehistory, 25, 205237.

Henshilwood, C. S., van Niekerk, K. L., Wurz, S., Delagnes, A., Armitage, S. J., Rifkin, R. F., Douze, K., Keene, P., Haaland, M. M., Reynard, J., Discamps, E., \& Mienies, S. S. (2014). Klipdrift Shelter, southern Cape, South Africa: Preliminary report on the Howiesons Poort layers. Journal of Archaeological Science, 45, 284-303.

Hodgkiss, T.P. (2013). Ochre use at Sibudu Cave and its link to complex cognition in the Middle Stone Age, Faculty of 
Science. Ph.D. thesis. The University of the Witwatersrand, Johannesburg.

Högberg, A., \& Lombard, M. (2016a). Indications of pressure flaking more than 70 thousand years ago at Umhlatuzana rock shelter. The South African Archaeological Bulletin, 71(203), 53-59.

Högberg, A., \& Lombard, M. (2016b). Still Bay point-production strategies at Hollow Rock Shelter and Umhlatuzana Rock Shelter and knowledge-transfer systems in southern Africa at about 80-70 thousand years ago. PLoS One, 11(12), $\mathrm{e} 0168012$.

Hogg, A. G., Hua, Q., Blackwell, P. G., Niu, M., Buck, C. E., Guilderson, T. P., Heaton, T. J., Palmer, J. G., Reimer, P. J., Reimer, R. W., Turney, C. S. M., \& Zimmerman, S. R. H. (2013). SHCal13 southern hemisphere calibration, 0-50,000 years cal BP. Radiocarbon, 55(4), 1889-1903.

Jacobs, Z., \& Roberts, R. G. (2008). Testing times: Old and new chronologies for the Howieson's Poort and Still Bay industries in environmental context. Goodwin Series, 10, 9-34.

Jacobs, Z., Roberts, R. G., Galbraith, R. F., Deacon, H. J., Grun, R., Mackay, A., Mitchell, P., Vogelsang, R., \& Wadley, L. (2008). Ages for the Middle Stone Age of southern Africa: Implications for human behavior and dispersal. Science, 322, 733-735.

Kaplan, J. M. (1989). 45.000 years of hunter-gatherer history as seen from Umhlatuzana rock shelter. M.A. thesis. University of Cape Town, South Africa.

Kaplan, J. (1990). The Umhlatuzana Rock Shelter sequence: 100 000 years of Stone Age history. Natal Museum Journal of Humanities, 2, 1-94.

Karkanas, P., \& Goldberg, P. (2018). Reconstructing archaeological sites: Understanding the geoarchaeological matrix. Hoboken: Wiley-Blackwell.

Karkanas, P., Brown, K. S., Fisher, E. C., Jacobs, Z., \& Marean, C. W. (2015). Interpreting human behavior from depositional rates and combustion features through the study of sedimentary microfacies at site Pinnacle Point 5-6, South Africa. Journal of Human Evolution, 85, 1-21.

Katz, O., Cabanes, D., Weiner, S., Maeir, A. M., Boaretto, E., \& Shahack-Gross, R. (2010). Rapid phytolith extraction for analysis of phytolith concentrations and assemblages during an excavation: An application at Tell es-Safi/Gath, Israel. Journal of Archaeological Science, 37, 1557-1563. https://doi.org/10.1016/j.jas.2010.01.016.

King, L. (1982). The Natal monocline; explaining the origin and scenery of Natal, South Africa. Pietermaritzburg: University of KwaZulu-Natal Press.

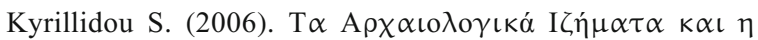

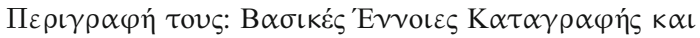

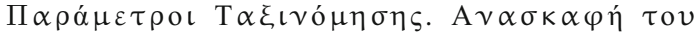

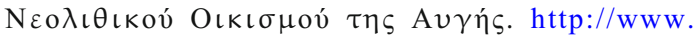
neolithicavgi.gr/wp-content/uploads/file/Unit\%20 Recording\%20Sheet.pdf [Handbook for sediment description in the field].

Larbey, C., Mentzer, S. M., Ligouis, B., Wurz, S., \& Jones, M. K. (2019). Cooked starchy food in hearths ca. 120 kya and 65 kya (MIS 5e and MIS 4) from Klasies River Cave, South Africa. Journal of Human Evolution, 131, 210-227.

Loftus, E., Stewart, B. A., Dewar, G., \& Lee-Thorp, J. (2015). Stable isotope evidence of late MIS 3 to Middle Holocene palaeoenvironments from Sehonghong rockshelter, eastern Lesotho. Journal of Quaternary Science, 30(8), 805-816.

Loftus, E., Pargeter, J., Mackay, A., Stewart, B. A., \& Mitchell, P. (2019). Late Pleistocene human occupation in the MalotiDrakensberg region of southern Africa: New radiocarbon dates from Rose Cottage Cave and inter-site comparisons. Journal of Anthropological Archaeology, 56, 101117.

Lombard, M. (2007). The gripping nature of ochre: The association of ochre with Howiesons Poort adhesives and Later Stone Age mastics from South Africa. Journal of Human Evolution, 53, 406-419.

Lombard, M. (2011). Quartz-tipped arrows older than $60 \mathrm{ka}$ : Further use-trace evidence from Sibudu, KwaZulu-Natal, South Africa. Journal of Archaeological Science, 38, 19181930.

Lombard, M., \& Haidle, M. N. (2012). Thinking a bow-and-arrow set: Cognitive implications of Middle Stone Age bow and stone-tipped arrow technology. Cambridge Archaeological Journal, 22, 237-264.

Lombard, M., \& Phillipson, L. (2010). Indications of bow and stone-tipped arrow use 64000 years ago in KwaZulu-Natal South Africa. Antiquity, 84, 635-648.

Lombard, M., Wadley, L., Jacobs, Z., Mohapi, M., \& Roberts, R. G. (2010). Still Bay and serrated points from Umhlatuzana rock shelter, KwaZulu-Natal, South Africa. Journal of Archaeological Science, 37, 1773-1784.

Lombard, M., Wadley, L., Deacon, J., Wurz, S., Parsons, I., Mohapi, M., Swart, J., \& Mitchell, P. (2012). South African and Lesotho Stone Age sequence updated. South African Archaeological Bulletin, 67(195), 123-144.

Lotter, M. G., Gibbon, R. J., Kuman, K., Leader, G. M., Forssman, T., \& Granger, D. E. (2016). A geoarchaeological study of the Middle and Upper Pleistocene levels at Canteen Kopje, Northern Cape Province, South Africa. Geoarchaeology, 31(4), 304-323.

Lowe, K. M., Shulmeister, J., Feinberg, J. M., Manne, T., Wallis, L. A., \& Welsh, K. (2016). Using soil magnetic properties to determine the onset of pleistocene human settlement at Gledswood Shelter 1, Northern Australia. Geoarchaeology, $31,211-228$.

Mackay, A., Stewart, B. A., \& Chase, B. M. (2014). Coalescence and fragmentation in the late Pleistocene archaeology of southernmost Africa. Journal of Human Evolution, 72, 26 51.

Madejová, J. (2003). FTIR techniques in clay mineral studies. Vibrational Spectroscopy, 31, 1-10.

Madella, M., \& Lancelotti, C. (2012). Taphonomy and phytoliths: A user manual. Quaternary International, 275, 76-83. https://doi.org/10.1016/j.quaint.2011.09.008.

Marshall, C.A.G. (1994). The stratigraphy of the Natal Group. Ph.D. thesis. The University of Natal, Durban.

McCall, G. S., \& Thomas, J. T. (2009). Re-examining the South African Middle-to-Later Stone Age transition: Multivariate analysis of the Umhlatuzana and Rose Cottage Cave stone tool assemblages. Azania, 44(3), 311-330.

Mentzer, S. (2014). Microarchaeological approaches to the identification and interpretation of combustion features in prehistoric archaeological sites. Journal of Archaeological Method and Theory, 21, 616-668. https://doi.org/10.1007/s10816012-9163-2. 
Mercader, J., Bennett, T., Esselmont, C., Simpson, S., \& Walde, D. (2009). Phytoliths in woody plants from the Miombo woodlands of Mozambique. Annals of Botany, 104, 91113. https://doi.org/10.1093/aob/mcp097.

Miller, C. E., Goldberg, P., \& Berna, F. (2013). Geoarchaeological investigations at Diepkloof Rock Shelter, Western Cape, South Africa. Journal of Archaeological Science, 40(9), 3432-3452.

Mitchell, P. (1994). Understanding the MSA/LSA transition: The pre-20 $000 \mathrm{BP}$ assemblages from new excavations at Sehonghong rock shelter Lesotho. Southern African Field Archaeology, 3, 15-25.

Mitchell, P. J. (2002). The archaeology of southern Africa. Cambridge: Cambridge University Press.

Mitchell, P. J. (2008). Developing the archaeology of Marine Isotope Stage 3. Goodwin Series, 10, 52-65.

Mohapi, M. (2012). Point morphology and the Middle Stone Age of Sibudu Cave, KwaZulu-Natal, South Africa. South African Archaeological Bulletin, 67(195), 5-15.

Mohapi, M. (2013). The Middle Stone Age point assemblage from Umhlatuzana rock shelter: A morphometric study. Southern African Humanities, 25, 25-51.

Mourre, V., Villa, P., \& Henshilwood, C. S. (2010). Early use of pressure flaking on lithic artifacts at Blombos Cave, South Africa. Science, 330, 659-662.

Mucina, L., \& Rutherford, M. C. (2006). The vegetation of South Africa, Lesotho and Swaziland. Pretoria: National Botanical Institute.

Mulholland, S. C., \& Rapp Jr., C. (1992). A morphological classification of grass silica-bodies. In G. Rapp Jr. \& C. S. Mulholland (Eds.), Phytolith systematics. Emerging issues, advances in archaeological and museum science (pp. 6589). New York: Plenum Press.

Müller, C. M., Pejcic, B., Esteban, L., Piane, C. D., Raven, M., \& Mizaikoff, B. (2014). Infrared attenuated total reflectance spectroscopy: An innovative strategy for analyzing mineral components in energy relevant systems. Scientific Reports, 4, 6764. https://doi.org/10.1038/srep06764.

Murungi, M. L. (2017). Phytoliths at Sibudu (South Africa): Implications for vegetation, climate and human occupation during the MSA. Johannesburg. Ph.D. thesis. University of the Witwatersrand, Johannesburg.

Murungi, M. L., \& Bamford, M. K. (2020). Revised taxonomic interpretations of Cyperaceae phytoliths for (paleo) botanical studies with some notes on terminology. Review of Palaeobotany and Palynology, 275, 104189.

Nel, W. (2009). Rainfall trends in the KwaZulu-Natal Drakensberg region of South Africa during the twentieth century. International Journal of Climatology, 29, 16341641.

Neumann, K., Strömberg, C. A. E., Ball, T., Albert, R. M., Vrydaghs, L., \& Cummings, L. S. (2019). International code for phytolith nomenclature 2.0. Annals of Botany, 124(2), 189-199. https://doi.org/10.1093/aob/mcz064.

Novello, A., Barboni, D., Berti-Equille, L., Mazur, J. C., Poilecot, P., \& Vignaud, P. (2012). Phytolith signal of aquatic plants and soils in Chad, Central Africa. Review of Palaeobotany and Palynology, 178, 43-58. https://doi.org/10.1016/j. revpalbo.2012.03.010.

Novello, A., Bamford, M. K., Van Wijk, Y., \& Wurz, S. (2018). Phytoliths in modern plants and soils from Klasies River,
Cape Region (South Africa). Quaternary International, 464, 440-459. https://doi.org/10.1016/j.quaint.2017.10.009.

Pargeter, J., Loftus, E., \& Mitchell, P. (2017). New ages from Sehonghong rock shelter: Implications for the late Pleistocene occupation of highland Lesotho. Journal of Archaeological Science: Reports, 12, 307-315.

de la Peña, P., Val, A., Stratford, D. J., Colino, F., Esteban, I., Fitchett, J. M., Hodgskiss, T., Matembo, J., \& Moll, R. (2019). Revisiting Mwulu's cave: New insights into the Middle Stone Age in the southern African savanna biome. Archaeological and Anthropological Sciences, 11(7), 32393266.

Pickering, R. (2006). Regional geology, setting and sedimentology of Sibudu Cave. Southern African Humanities, 18(1), 123-129.

Piperno, D. R. (1988). Phytolith analysis: An archaeological and geological perspective. San Diego: Academic Press.

Piperno, D. R. (2006). Phytoliths: A comprehensive guide for archaeologists and paleoecologists. Lanham: AltaMira Press. https://doi.org/10.1177/0959683606073496.

Pollard, M., Batt, C., Stern, B., \& Young, S. M. M. (2007). Analytical chemistry in archaeology. Cambridge: Cambridge University Press.

Reynard, J. P., Discamps, E., Wurz, S., van Niekerk, K. L., Badenhorst, S., \& Henshilwood, C. S. (2016). Occupational intensity and environmental changes during the Howiesons Poort at Klipdrift Shelter, southern Cape, South Africa. Palaeogeography, Palaeoclimatology, Palaeoecology, 449, 349-364.

Roberts, P., Lee Thorp, J. A., Mitchell, P. J., \& Arthur, C. (2013). Stable carbon isotopic evidence for climate change across the late Pleistocene to early Holocene from Lesotho, southern Africa. Journal of Quaternary Science, 28, 360-369.

Rossouw, L. (2009). The application of fossil grass-phytolith analysis in the reconstruction of late Cainozoic environments in the South African interior. Bloemfontein: University of the Free State.

Rots, V., Lentfer, C., Schmid, V. C., Porraz, G., \& Conard, N. J. (2017). Pressure flaking to serrate bifacial points for the hunt during the MIS5 at Sibudu Cave (South Africa). PLoS One, 12, e0175151.

Sherman Hsu, C. P. (1997). Infrared spectroscopy. In F. A. Settle (Ed.), Handbook of instrumental techniques for analytical chemistry (pp. 247-284). Upper Saddle River: Prentice Hall.

Stewart, B. A., Parker, A. G., Dewar, G., Morley, M. W., \& Allot, L. F. (2016). Follow the Senqu: Maloti-Drakensberg paleoenvironments and implications for early human dispersals into mountain systems. In S. C. Jones \& B. A. Stewart (Eds.), Africa from MIS6-2 population dynamics and palaeoenvironments (pp. 247-272). New York: Springer.

Twiss, P. C., Suess, E., \& Smith, R. M. (1969). Morphological classification of grass phytoliths. Soil Science Society of America Proceedings, 33, 109-115.

Vahur, S., Teearu, A., Peets, P., Joosu, L., \& Leito, I. (2016). ATR-FT-IR spectral collection of conservation materials in the extended region of $4000-80 \mathrm{~cm}^{-1}$. Analytical and Bioanalytical Chemistry, 408, 3373-3379. https://doi. org/10.1007/s00216-016-9411-5.

Villa, P., Delagnes, A., \& Wadley, L. (2005). A late Middle Stone Age artifact assemblage from Sibudu (KwaZulu-Natal): 
Comparisons with the European Middle Paleolithic. Journal of Archaeological Science, 32, 399-422.

Villa, P., Soressi, M., Henshilwood, C. S., \& Mourre, V. (2009). The Still Bay points of Blombos Cave (South Africa). Journal of Archaeological Science, 36, 441-460.

Villa, P., Soriano, S., Tsanova, T., Degano, I., Higham, T. F. G., d'Errico, F., Backwell, L., Lucejko, J. J., Colombini, M. P., \& Beaumont, P. B. (2012). Border Cave and the beginning of the Later Stone Age in South Africa. Proceedings of the National Academy of Sciences, 109(33), 13208-13213.

Volman, T.P. (1981). The Middle Stone Age in the southern Cape. $\mathrm{Ph} . \mathrm{D}$. thesis. University of Chicago, Chicago.

Wadley, L. (2005). A typological study of the final Middle Stone Age stone tools from Sibudu Cave, KwaZulu-Natal. South African Archaeological Bulletin, 60, 51-63.

Wadley, L. (2007). Announcing a Still Bay industry at Sibudu Cave, South Africa. Journal of Human Evolution, 52, 681689.

Wadley, L. (2010). Were snares and traps used in the Middle Stone Age and does it matter? A review and a case study from Sibudu, South Africa. Journal of Human Evolution, 58, 179-192.

Wadley, L., \& Jacobs, Z. (2006). Sibudu Cave: Background to the excavations, stratigraphy and dating. Southern African Humanities, 18, 1-26.

Wadley, L., Sievers, C., Bamford, M., Goldberg, P., Berna, F., \& Miller, C. (2011). Middle Stone Age bedding construction and settlement patterns at Sibudu, South Africa. Science, 334, 1388-1391.

Weiner, S. (2010). Microarchaeology. Beyond the visible archaeological record. Cambridge: Cambridge University Press. https://doi.org/10.1017/CBO9780511811210.

Wurz, S. (2002). Variability in the Middle Stone Age lithic sequence, 115,000-60,000 years ago at Klasies River, South Africa. Journal of Archaeological Science, 29, 1001-1015.

Publisher's Note Springer Nature remains neutral with regard to jurisdictional claims in published maps and institutional affiliations. 